\title{
FILIAL RESPONSIBILITY EXPECTATIONS AMONG
}

$$
\begin{gathered}
\text { ADULT CHILD - OLDER PARENT PAIRS } \\
\text { by }
\end{gathered}
$$

\section{Raeann R. Kunkle Hamon}

Dissertation submitted to the Faculty of the

Virginia Polytechnic Institute and State University

in partial fulfillment of the requirements for the degree of DOCTOR OF PHILOSOPHY

in

Family and Child Development

APPROVED :

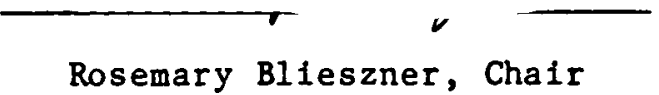

Rosemary Blieszner, Chair

Vdy A. Mancini

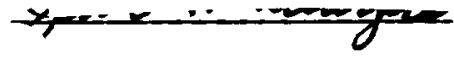

Janet K. Sawyers

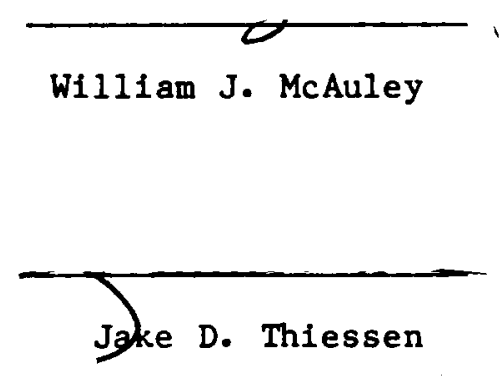

May, 1988

Blacksburg, Virginia 
FILIAL RESPONSIBILITY EXPECTATIONS AMONG

ADULT CHILD - OLDER PARENT PAIRS

by

Raeann R. Kunkle Hamon

Committee Chalrperson: Rosemary Blleszner

Family and Child Development

(ABSTRACT)

The current study is an investigation of filial responsibility expectations endorsed by a randomly selected sample of 144 elderly parent - adult child pairs from the Harrisburg area of Pennsylvania. Descriptive statistics suggested that most older parents and adult children interpreted the filial role to include a great deal of emotional support and discussion of important matters and available resources. Both generations perceived living close and writing letters to parents on a weekly basis as less important. Parents were more likely to disapprove of receiving financial assistance from chlldren, living with children, and having children adjust their work schedules to help them than were their offspring. Robinson's statistical measure of agreement, which examined the amount of consensus between generations, revealed that there was a moderate level of agreement between parents and their children on filial responsibility expectations. Multiple regression analyses indicated that amount of agreement on filial norms did not have an impact on parental well-being, however. 
ACKNOWLEDGEMENTS

I wish to extend my appreclation to several very special Individuals for their contribution to the successful completion of this project. First and foremost, I want to express my gratitude to Dr. Rosemary Blieszner for serving as my mentor and model. Dr. Blieszner's degree of professionalism has been an inspiration for me in my own career development.

My committee members also deserve a great deal of acknowledgment for their assistance with this study, particularly in its formative phase. I want to thank Dr. Jay Mancini, Dr. Jim McAuley, Dr. Janet Sawyers, and Dr. Jake Thiessen for serving as expert advisors.

I would also like to thank Dr. Marlin Eby for his willingness to serve as my statistical consultant, as my distance from Virginia Tech precluded easy access to assistance and facilities there. Last, but not least, I want to thank my husband for his unfailing support and encouragement throughout this entire process. 


\section{TABLE OF CONTENTS}

Abstract......................................1

Acknowledgements................................ii

List of Tables...................................

Filial Responsibility Expectations Among Adult

Child - 0lder Parent Pairs

Theoretical Background............................

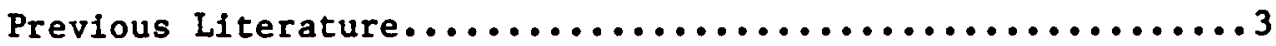

Methods......................................

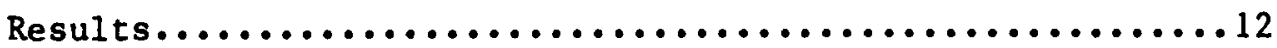

Discussion....................................

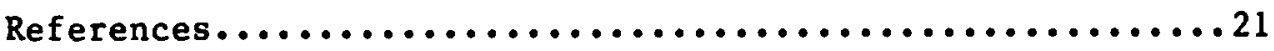

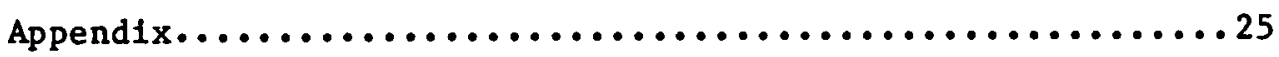

Tables...................................... 27

Appendix A. Literature Review........................ 32

Appendix B. Methodology............................. 52

Tables....................................... 74

Appendix C. Telephone Interview Schedule.................82

Appendix D. Research Instrument and Correspondence

to Adult Children................................. 85

The Cover Letter for First Mailing........................ 86

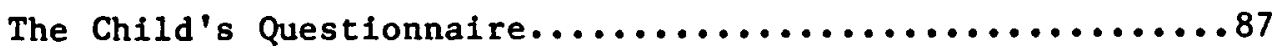

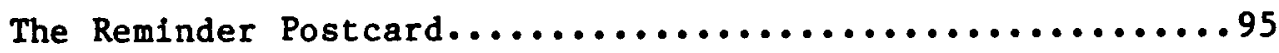

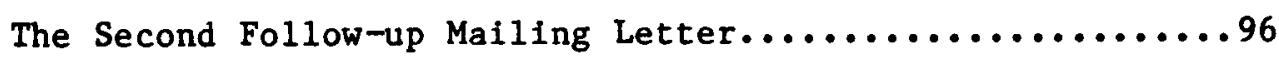

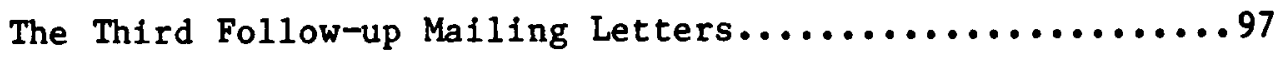


Appendix E. Research Instrument and Correspondence

to $01 d e r$ Parents.................................... 99

The Cover Letter for First Mailing.......................

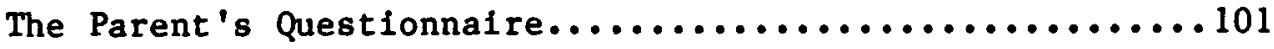

The Reminder Postcard..........................110

The Second Follow-up Mailing Letter.................111

The Third Follow-up Mailing Letters.................112

Appendix F. Supplementary Results and Discussion.............114

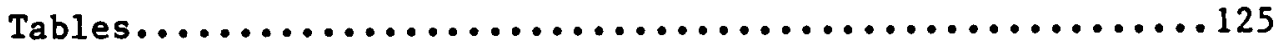

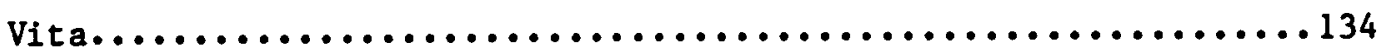




\section{LIST OF TABLES}

Table

Page

1 Endorsement of Hamon Filial Responsibility

Items by Adult Children and Their Elderly Parents ........27

2 Coefficient of Agreement for Aged Parent - Adult

Child Pairs on the Hamon Filial Responsiblity Scale.......28

3 Summary of Multiple Regression Analysis for Parental

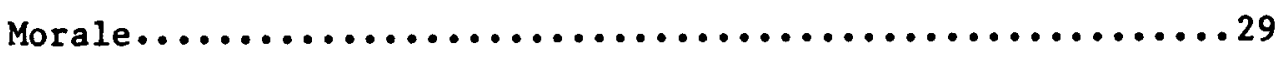

4 Average Morale Scores for Aged Parents by Religious

Preference and Level of Health.................... 30

5 Average Morale Scores for Aged Parents by Adequacy of

Income and Level of Health.......................... 31

B-1 Telephone Screening Response Rates...................... 44

B-2 Demographic Characteristics of Adult Children and

Elderly Parents................................

B-3 Means and Standard Deviations of the Hamon Filial

Responsibility Scale Items for Children and Parents.......77

B-4 Intercorrelations of Children's Responses to Hamon

Filial Responsibility Scale.....................

B-5 Intercorrelations of Parents' Responses to Hamon

Filial Responsibility Scale........................79

B-6 Factor Loadings of Four Dimensions of Hamon Filial

Responsibility Scale Items for Adult Children...........80

B-7 Factor Loadings of Four Dimensions of Hamon Filial

Responsibility Scale Items for Older Parents.............81 
F-1 Summary of Multiple Regression Analysis for Filial

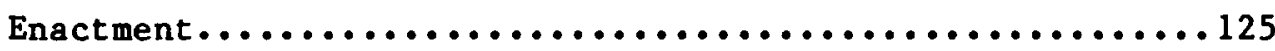

F-2 Average Enactment Scores for Adult Children by

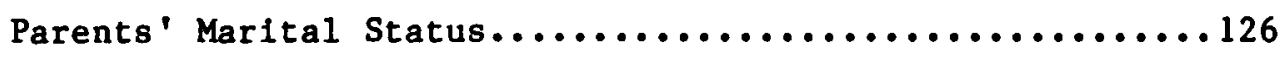

F-3 Average Enactment Scores for Adult Children by

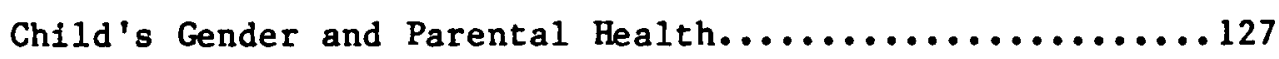

F-4 Beta Weights for the Relationship Between Enactment

and Number of Dependent Children by Geographical

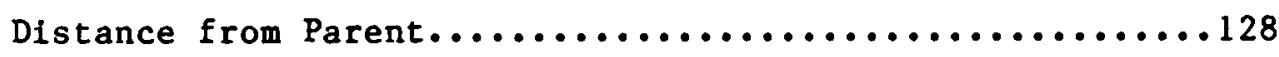

F-5 Beta Weights for Relationship Between Enactment and

Child's Amount of Affection for Parent by Geographical

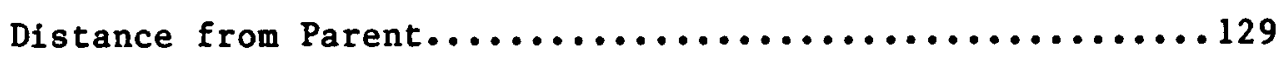

F-6 Summary of Multiple Regression Analysis for Social

Provisions................................... 130

F-7 Average Social Provision Scores for Levels of

Significant Independent Variables........................

F-8 Average Social Provision Scores Reported by Aged Parents by Child's Marital Status and Parent's Gender............132

F-9 Beta Weights for the Relationship Between Social

Provisions and Child's Affection for Parent by Child's

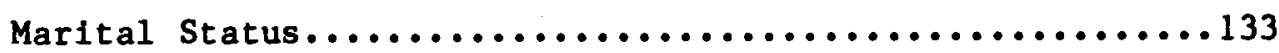


As the elderly segment of the population grows in both number and proportion, more and more adult children are experiencing the obligations and privileges of filial duties, making this aspect of the intergenerational relationship of great concern to today's families. Despite the increasing normativity of relationships with older and older family members, a great deal of ambiguity surrounds intergenerational roles. What types of attitudes and behaviors can aging parents rightfully expect of their adult children? Similarly, with various competing demands (employment outside the home, dependent children, limited resources of time, energy and money, and so on) and increasing intervention by governmental programs (Medicare, Meals on Wheels, Senfor Centers, and others) what should adult children expect of themselves with regard to their roles as responsible offspring? Do parents and children agree as to what the filial role entails? And finally, does the amount of consensus between the generations' expectations influence the personal we11being of older parents? These are questions addressed in the present investigation.

\section{Theoretical Background}

Role theory and symbolic interaction provide the theoretical foundation for this study. According to symbolic interactionists, if one wants to understand social and human behavior, the most fruitful area to study is beliefs and values that individuals acquire from interacting with others. Cognitions and other mentalistic 
processes offer the most direct explanations of interactive behavior (Burr, Leigh, Day \& Constantine, 1979).

Roles are comprised of a collection of social norms -- beliefs about how people ought to behave in a certain position. Although role definition permits a great deal of individual discretion for the role player, roles always consist of some socially shared expectations (Burr, Leigh, Day, \& Constantine, 1979). Role expectations, or sets of cognitions and beliefs that serve as a description of appropriate conduct for individuals who occupy specific social positions, were the focus of this study. These beliefs dictate the rights and privileges, as well as the duties and obligations of the social position of adult child in relation to persons occupying the complementary position in the social system, namely parent. Not only do expectations outline which acts the filial role occupants are and are not to perform, but they also dictate "how" persons "should" conduct themselves in this position. Expectations also include time and spatial dimensions so that people expect filial role behavior to occur at the proper time and in the appropriate place (Sarbin, 1968; Sarbin \& Allen, 1968).

Roles, then, do not exist in a vacuum; they involve a dynamic interface of expectations of two or more individuals. In the case of the filial role, the expectations of parents and their adult children seem to be preeminent. Consequently, in this study I used older parent - adult child dyads as the unit of analysis since the views of 
both role partners are necessary to adequately investigate the filial role.

When measuring both generations on a singular subject -- filial responsibility norms -- the possibility exists that the expectations of the two generations will not be congruent. Thus, amount of consensus on role expectations, or how much the parents and their children agree or disagree on role expectations, is also important. When people agree on what they expect of the role performer, consensus exists. The amount of expectation consensus within the dyads has implications for the satisfaction pairs receive from specific relationship interactions and for individual well-being, as we11. Thus, in this investigation $I$ also examined the effect of filial expectation consensus or dissensus on the well-being of older parents.

\section{Previous Literature}

A few researchers have examined filial responsibility expectations held by elderly parents and/or adult children. In general, this research has been diverse in its focus, method, and intent. In addition, most investigators have used a small and limited number of filial expectation items.

Some researchers have considered what elderly parents expect of their adult offspring. Streib (1965) found that a sample of 291 retired parents placed greatest emphasis on the maintenance of close affectional ties with their adult children. More recently, qualitative and quantitative data from a small sample of 23 older 
adults revealed that parents desire affection, thoughtfulness, and open, honest, and frequent communication from their adult offspring; they deemed direct caregiving and residential proximity less important (Blieszner \& Mancini, 1987).

In analyses of data from 595 low-income elderly parents in Philadelphia, Seelbach $(1977,1978, \& 1981)$ and his associates (Hanson, Sauer, \& Seelbach, 1983; Seelbach \& Sauer, 1977) examined filial responsibility expectations and realizations, variables associated with different levels of expectations, and predictors of types of assistance provided by adult children. Results suggested gender differences; females were more likely than males to think that old parents who do not wish to live alone or who are physically unable to care for themselves should live with one of their children (Seelbach, 1977). Statistically significant differences between blacks and whites were nonexistent (Seelbach, 1981). 0lder, widowed, low-income, and frail persons tended to expect more from their offspring; Seelbach (1978) noted that filial expectancies of old parents are usually indicative of their level of need. When comparing expectations with actual assistance received, parents who were female, widowed, had low-income, and were in poor health were likely to be profiting from filial responsibility realizations (Seelbach, 1978).

Research on the impact of rural or urban environments on filial responsibility expectations of single cohort groups has yielded contradictory results. Dinkel (1944) found that younger rural 
residents were more likely to endorse filial obligation norms than their urban student counterparts. Conversely, a study by Sauer, Seelbach, and Hanson (1981) indicated that urbanites were significantly more likely to endorse filial norms. Among a sample of Caucasian students and their parents, Wake and Sporakowski (1972) found minimal and nonsignificant differences in filial attitudes between urban and rural residents.

Studies have indicated that aged parents have differing expectations of family and nonfamily members. Mancini and Simon (1984) compared the expectations of support from family, close friends and casual friends in the areas of assistance, social integration, and intimacy. Findings from their sample of 91 elderly participants indicated that expectations for support from family members exceeded those for friends, especially casual friends, particularly in the area of assistance. Expectations of family were greater in the way of lending small and large amounts of money in an emergency, giving unsolicited advice, intervening when personal safety is at risk, and providing housing when circumstances demand it. Simllarly, Sanders and Seelbach (1981) analyzed age differences in preferences for family versus nonfamily sources of care for the old with telephone interview data from 450 individuals ranging from 18 to 90 years old. Although there were no significant differences in average ages of participants preferring family sources and nonfamily sources, there was a greater preference for family care among whites than blacks. 
Brody (1981) and her colleagues (Brody, Johnsen, \& Fulcomer, 1984; Brody, Johnsen, Fulcomer, \& Lang, 1983) are responsible for one of the sparse number of studies that analyzed the attitudes and beliefs of more than one generation simultaneously. Using a sample of 433 women from three generations ( 225 of whom belonged to 75 family triads), they investigated opinions about appropriate filial responsibility behaviors, and personal preferences among types of providers of different types of services. Overall, the sense of filial responsibility was strong among the three generations of women; most felt that the old should be able to depend on adult children for help (Brody, 1981; Brody et al., 1983). The majority of these women believed that adult children should adjust their family schedules and help meet expenses of professional health care for the impaired elderly mother when needed. They did not view adjustment of work schedules and sharing households as appropriate, however. A11 three generations ranked the adult child first over five other potential providers (other relative, friend/neighbor, volunteer/civic or church group, pension/insurance, and government) for intimate functions such as confidant and financial manager (Brody et al., 1984). There were generational differences, however. The middle generation women were less likely than grandmothers or granddaughters to prefer adult children as providers of housework, personal care, and financlal support (Brody, 1981). The oldest generation was most receptive to formal services for the elderly (Brody et al., 1983). 
Existing research also indicates that parental expectations of filial responsibility may affect older parents' levels of well-being. Filial responsibility expectations are inversely associated with parental morale (Quinn, 1983; Seelbach \& Sauer, 1977); the more parents expected from their children in the way of obligations surrounding care during illness, financial help, living nearby, visiting patterns and general feeling of duty, the lower was their life satisfaction. Seelbach and Sauer (1977) proposed that those parents with extensive expectations may be "out of tune with their offsprings' expectations" (p. 498). Similarly, in a study of 50 elderly parent-adult child dyads, parental well-being was associated with parental perceptions that their children will fulfill their roles as responsible others if crisis necessitates them to do so (Schlesinger, Tobin, \& Kulys, 1981).

In light of the available research findings, I considered the individual expectations of parents and their adult children in this study. I hypothesized that both aged parents and their adult children endorse filial responsibility items that are of an emotional nature (talk over matters of personal importance, be together on special occasions, give emotional support, and so on) to a greater extent than those items that are instrumental (provide financial support, adjust family and work schedules to help, and so on) in their focus. This portion of the study replicated previous research. The current investigation also extended available knowledge by computing levels of consensus between the generations and then 
determining whether degree of consensus had an impact on the wel1being of older parents. I hypothesized that parental morale or sense of well-being is directly and positively related to extent of consensus (agreement) between generational filial responsibility expectations.

\section{Methods}

\section{Respondents}

One hundred forty-four elderly parent and adult child pairs from the Harrisburg area of Pennsylvania were participants in this study. I collected data during the Fall of 1986 using a two-stage probability design as described by Dillman (1978). First, using a systematic random sample of the Harrisburg telephone directory, I screened households for parents who were 65 years of age or older. If no residents were parents in their advanced years, I asked persons 21 years or older with aged parents to participate. In either case, when more than one resident was eligible for inclusion, I used a table of random numbers to select the study participant. Questioning continued with the appropriate persons, when possible, to verify their address and to elicit the names and addresses of their randomly selected pair partners. The telephone screening yielded an initial pool of $53 \%$ of total households contacted ( 439 unuseables, 185 refusals--including hang-ups, and 209 acceptances). (Refer to Table $B-1)$.

The second phase of the sampling design involved mailing separate questionnaires to each member of the pair. I typed names of 
the referent parent or child on the corresponding personalized cover letter in order to remind the participant which parent/child he or she was to consider in responding to the questions. A total of 328 individuals completed the questionnaire, representing a return rate of $78 \%$ after three follow-up contacts. Because the purpose of this study was to examine the level of agreement between parents and children on filial responsibility expectations, I examined only the data of 144 completed pairs ( $87.8 \%$ of the respondents) for the present report.

01der parents ranged in age from 60 to 94 years, with a mean of 71 years. There were more women (58.7\%) than men (41.3\%), and more married parents $(65.5 \%)$ than widowed $(31.7 \%)$ and divorced $(2.8 \%)$. The majority of the sample was white $(97.2 \%)$, with the remaining portion being black (2.1\%) and Native American (.7\%). Due to the preponderance of white participants, I cannot generalize findings to non-white populations. In the sample, $23.1 \%$ had annual incomes of less than $\$ 10,000,31.5 \%$ had gross incomes of $\$ 10,000$ to $\$ 19,999$, $17.7 \%$ grossed between $\$ 20,000$ and $\$ 29,999$, and the remaining $27.7 \%$ made $\$ 30,000$ or more. Although the number of living children ranged from one to ten, the average number of living offspring for this sample of older parents was 3.28. With the exception of the racial distribution, the older parents of this sample were comparable to the older segment of the Harrisburg area.

Adult children were 23 to 66 years of age, with an average age of 41 years. Thirty four percent were male and $66 \%$ were female. The 
largest portion of children were first-borns ( $41 \%$ ), with $33 \%$ secondborns, $11.8 \%$ third-borns, $5.6 \%$ fourth-borns and $8.3 \%$ beyond that. Like their parents, most $(76.4 \%)$ of the children were married with fewer being widowed (3.5\%) than divorced or separated (9.7\%), and $10.4 \%$ never marrying at all. Gross family income tended to be higher for the children than for the parents. Only $4.4 \%$ had annual incomes of less than $\$ 10,000,10.3 \%$ had $\$ 10,000$ to $\$ 19,999,21.3 \%$ earned $\$ 20,000$ to $\$ 29,000$, and $63.9 \%$ grossed $\$ 30,000$ or above. Adult children had an average of 1.88 offspring, with an average of 1.27 of them dependent. Although comparable in most other areas, the sample of adult children had a slightly higher ratio of females to males than is found in the greater Harrisburg area. (Refer to Table B-2). Measurement

Dillman's (1978) specifications guided the construction of the survey instruments. Questionnaires for both the parents and the children included items to ascertain their filial responsibility expectations -- their beliefs about what obligations adult offspring have with regard to meeting the needs of aging parents. I adapted items from previous research (Brody, Johnsen, Fulcomer \& Lang, 1983; Seelbach \& Sauer, 1977; Quinn, 1983) to create the 16-item Hamon Filial Responsibility Scale for this study. I expanded upon existing filial responsibility scales in order to include items that tapped emotive, instrumental, contact, and communicative components of filial responsibility. Items included in the scale explore attitudes towards what people typically think of as filial responsibility, such 
as helping when sick, visiting or writing once a week, and giving emotional support. In addition, I included items that address many of the current issues of contemporary society. For example, with more women -- the traditional caregivers -- in the work force, it was important to learn whether filial responsibilfty expectations encompass children adjusting their work schedules to help. So too, in the context of a nation whose families are greatly mobile, it was significant to know whether filial responsibility expectations include family members being together on special occasions. Finally, in an industrialized country that offers governmental assistance to the aged, one might suspect that filial responsibility entails helping parents to understand governmental resources that are available to them. Thus, I designed the Hamon Filial Responsibility Scale to take current trends into account, as they might affect the parent-child relationship, particularly with regard to filial responsibility expectations and norms. The Hamon Filial Responsibility Scale items appear in the appendix.

Participants responded to each item using a 4-point Likert scale that ranged from (4) strongly agree to (1) strongly disagree, with a possible scale score of 16 to 64 . Means of the items ranged from 2.29 to 3.49 for children and 2.18 to 3.42 for older parents. (See Table B-3 in Appendix B for a complete listing of means and standard deviations for the items). Internal consistency (Cronbach's alpha) of the Hamon Filial Responsibility Scale was . 86 for the parent sample and .85 for the sample of adult children. 
The measure of the aging parents' psychological well-being was the revised version of the Philadelphia Geriatric Center Morale Scale (Lawton, 1975). This 17-item scale required dichotomous responses from participants and assessed three dimensions of morale: Agitation, Attitude Toward Own Aging, and Lonely Dissatisfaction. Information about the scale's development, validity and reliability is available in Lawton $(1972,1975)$. The Cronbach's alpha of this scale for the present sample of older parents was .84 .

\section{Results}

\section{Individual Expectations}

Descriptive statistics provided a general picture of the expectations of the two generations. Table 1 depicts the individual items and their endorsement by both parents and children. Among the adult children, the three most strongly endorsed norms suggest that grown offspring interpret the filial role as one that includes a great deal of emotional support, and discussion of important matters and available resources. The next most popular grouping of items reveals that adult children perceive of their role as inclusive of the provision of instrumental support. They believed that responsible children would or should sacrifice personal freedom, adjust their family schedules, provide financial assistance, and open their home to their parents if the need should arise. In contrast, the majority of adult children disagreed or strongly disagreed with two items. Adult children thought it was inappropriate to ask them as responsible offspring to write to their parents once a week or to 
live close to their parents. The sample of adult children was almost equally divided on the belief that children who live nearby after they grow up should visit their parents at least once a week; $51.3 \%$ either agreed or strongly agreed with that statement.

\section{Insert Table 1 about here}

In general, the percentages of endorsement among the elderly parent subgroup were not as high as those among their adult children. Older parents endorsed with highest frequency the same three items that topped the list for adult children; the role of the child as a confidant is reconfirmed as parents, too, thought children should talk to them about important issues in their lives. Also of value to parents is that their children be with them on special occasions. Many indicated that they thought it appropriate that children sacrifice some personal freedom to take care of them if they need it, suggesting a desire to feel secure in knowing that their needs would be met should they become incapable of independence. Like their adult children, most elderly parents thought it unnecessary for children to live close to their parents or write to their parents at least once a week. Unlike their offspring, however, parents disapproved of recelving financial assistance from children, living with their children, and having children adjust their work schedules to help them. 


\section{Intergenerational Consensus}

In an effort to examine the amount of consensus between the generations, I submitted parent and child responses to Robinson's (1957) statistical measure of agreement. Unlike measures of correlation which require only that paired values be linked by a linear relationship, agreement requires that paired values be identical (Robinson, 1957, p. 19). For example, perfect correlation occurs if the second element of the pair $(y)$ is always equal to a multiple (a) of the first element of the pair ( $x$ ) plus a constant (b) $(y=a x+b)$. The multiple and constant must be the same for all pairs. In contrast, perfect agreement can only occur if the second element (y) is always equal to the first element $(y=x)$. Thus, perfect agreement implies perfect correlation, but not vice versa. The agreement coefficient ranges from 0 , which indicates perfect disagreement, to 1 , which suggests perfect agreement. For example, If Parent A strongly agreed that "adult children should give their parents financial help," but his/her Child A strongly disagreed with that statement, there would be perfect disagreement. On the other hand, if both Parent B and Child B strongly disagreed with the norm, there would be perfect agreement. Table 2 displays the agreement coefficients for the sixteen individual items, as well as a total response measure. 
Insert Table 2 about here

Across the 130 pairs having complete data for all sixteen items, Robinson's measure of agreement was . 5819; parents and their adult children were in moderate agreement with regard to filial norms. Individual items with high amounts of agreement related to residential proximity of children to parents, giving parents advice, and appropriate types and frequency of contact. The greatest divergence of agreement was evidenced in the areas of emotional and financial assistance to parents.

Parental Morale

In order to identify variables that would be helpful in explaining differences in morale scores among older parents, I conducted exploratory analyses in the form of stepwise multiple regression. Among the variables considered were two measures of parent-child agreement. Each measure assigned a value to each parent-child pair. The first measure involved a comparison of the parent and child responses on each of the 16 items. These comparisons were summarized by calculating Robinson's measure of agreement across all 16 items. The second value was a measure of agreement of the parent's and child's total (for the 16 items) scores. The two agreement measures were unimportant in explaining morale differences among elderly parents. Thus, the data did not support the major research hypothesis that consensus (agreement) 
between generational filial responsibility expectations is positively related to parental morale. Consequently, the final regression model did not include either of the agreement measures. (Refer to Table 3 for variables included in the regression model).

\section{Insert Table 3 about here}

The overall regression model accounted for $40.5 \%$ of the variability in parental morale. Two interaction effects, religious preference with self-perceived health $(p=.04)$ and perceived adequacy of income with perceived health $(p=.03)$ were statistically significant. I used a multiple comparison procedure (pairwise ttests) to isolate specific differences for each case of significant interaction. With regard to the interaction between religious preference and parental health, both Protestants $(p<.01)$ and Catholics $(p=.08)$ reporting good health had higher average morale scores than those reporting poor health $(p=.12)$. However, for those with other religious preferences, the trend was reversed $(p=, 12)$. See Table 4 for the set of means that depicts the interaction of religious preference and health.

\section{Insert Table 4 about here}

When considering the interaction between parental perception of income adequacy and parental perception of health, the average morale 
score was higher among those with adequate income and good health $(p=.14)$ (See Table 5). For those with inadequate income, the trend was reversed; with inadequate income average morale scores were higher for elderly parents reporting poor, rather than good health. Said differently, those reporting good health and adequate income had higher average morale scores than those with good health and inadequate income $(p=076)$. Conversely, parents reporting poor health averaged higher morale scores if they had inadequate incomes $(p=.43)$

Insert Table 5 about here

Discussion

As hypothesized, this study reconfirmed the strength of filial responsibility norms in American society; both parents and adult chlldren recognize certain filial obligations to be fulfilled by adult offspring. Also as expected, the adult child's significance in the emotional realm emerged as predominant for both children and parents, supporting the evidence accumulated by several other researchers (Blieszner \& Mancini, 1987; Brody et. al, 1984; Stre1b, 1965). Instrumental assistance appears to be less important among this sample as well, supporting Seelbach's (1984) assertion that the primary role of today's American family serves best as a major source of affectional and emotional support. 
The amount of endorsement of the filial responsibility items seems to be responsive to current trends in the American family. For one, although the desire for independence appears to be the norm for older parents, as evidenced in the low levels of endorsement for financial support, adjustments to family and work schedules, and the like, the data do support Schlesinger and colleagues' (1981) contention that there is security in knowing that one's child will respond when needed. The majority of both parents and children endorsed the item stating that children should feel responsible for their parents. Second, parents and children seem to have made adjustments to greater mobility among family members. Although both generations highly endorsed being together on spectal occasions, they deemed living close and writing and visiting once a week as less important. Third, like Sussman (1976), in this research I argue that with increasing governmental intervention, the nature of filial responsibility has changed. In an increasingly complex society, the adult child becomes an important source of affectional and emotional support and advice, and is particularly instrumental in helping parents learn of and utilize governmental resources that will prolong independent 1iving. An additional fillal norm that the current study did not measure, which appears to be important in today's society, is the adult child as coordinator and monitor of services and care to aging parents (Cicirelli, 1981). Future studies should examine the adult child's role as coordinator of services. Finally, the difference with which parents and children endorsed the filial 
responsibility items might explain the existence of filial anxiety "the state of worry or concern about the anticipated decline and death of an aging parent and one's abilities to meet anticipated caregiving needs" (Cicirelli, 1987, p. 5). In general, the percentage of endorsement of the items was greater for adult children than for their aged parents. Children may experience some undue anxiety, to the extent that their parents do not seem to expect as much from them as they do of themselves.

From a role theory perspective, one might not be surprised to discover at least a moderate level of agreement between the generations with regard to expected behavior and attitudes for adult offspring. Through the interaction process, adult children are likely to have modified their conception of the filial role in response to the feedback they have received from their parents and other reference persons. Since role-making is a dynamic process, family practitioners could greatly assist the family of later life by facilitating intergenerational communication, particularly with regard to fillal expectations. More practical strategies for encouraging honest discussions concerning appropriate filial behavior might reduce filial anxiety and help older parents realistically plan for future events. These strategies should promote direct communication of needs and desires to reduce the likelihood of misinterpretation and disappointment.

Finally, in explaining morale differences among aging parents, degree of intergenerational consensus on filial expectations appears 
irrelevant. Although parents' own expectations of filial responsibility may affect their level of morale (Quinn, 1983; Seelbach \& Sauer, 1977), consensus between the generations with regard to filial norms appears to be less crucial. Instead, what again emerges in explaining parental well-being has to do with their living situation (Larson, 1978), particularly perceptions of their situation in comparison to others' life circumstances. The interactive effects of health with religlous preference and health with income adequacy suggest that although health is important in understanding morale, it can be modified by intervening variables. In conclusion, this study has made several important contributions to the literature on intergenerational relationships in later life. First, it has replicated and, in most instances, reconfirmed existing data that describe the nature of the filial role in light of social changes. Second, this study has expanded the list of filial expectation items to include a multiplicity of potential role norms for adult offspring in an effort to get a more comprehensive and timely conception of this role. Third, the analysis utilized a measure of agreement in order to go beyond comparisons of frequencies of endorsement of various filial expectations in understanding generational differences and similarities. Finally, the study examined level of agreement in an effort to determine impact of intergenerational consensus on parental morale. 


\section{References}

Blieszner, R., \& Mancini, J.A. (1987). Enduring ties: Older Adults' parental role and responsibilities. Family Relations, 36, 176-180.

Brody, E.M. (1981). "Women in the middle" and family help to older people. The Gerontologist, 2, 471-480.

Brody, E.M., Johnsen, P.T., \& Fulcomer, M.C. (1984). What should adult children do for elderly parents? Opinions and preferences of three generations of women. Journal of Gerontology, 39, 736746.

Brody, E.M., Johnsen, P.T., Fulcomer, M.C., \& Lang, A.M. (1983). Women's changing roles and help to elderly parents: Attitudes of three generations of women. Journal of Gerontology, 38, 597-607. Burr, W.R., Leigh, G.K., Day, R.D., \& Constantine, J. (1979). Symbolic interaction and the family. In W.R. Burr, R. Hill, F.I. Nye, and I.L. Reiss (Eds.), Contemporary theories about the family: Vol. 2 (pp. 42-111). New York: Free.

Cicirelli, V.G. (1981). Helping elderly parents: The role of adult children. Boston: Auburn House.

Cicirelli, V.G. (1987). Filial anxiety in relation to care of elderly parents. Paper presented at the 40th Annual Scientific Meeting of the Gerontological Society of America, Washington, DC, November . 
Dillman, D.A. (1978). Mail and telephone surveys: The total design method. New York: John Wiley \& Sons.

Dinkel, R. (1944). Attitudes of children toward supporting aged parents. American Sociological Review, 9, 370-379.

Hanson, S.L., Sauer, W.J., \& Seelbach, W.C. (1983). Racial and cohort variations in filial responsibility norms. The Gerontologist, $23,626-631$.

Larson, R. (1978). Thirty years of research on the subjective wellbeing of older Americans. Journal of Gerontology, 33, 109-125. Lawton, M.P. (1975). The Philadelphia Geriatric Center Morale

Scale: A revision. Journal of Gerontology, 30, 85-89. Lawton, M. P. (1972). The dimension of morale. In D.P. Kent, R. Kastenbaum, and S. Sherwood (Eds.), Research planning and action for the elderly (pp. 144-165). New York: Behavioral Sciences. Mancini, J.A., \& Simon, J. (1984). Older adults' expectations of support from family and friends. Journal of Applied Gerontology, 3, $150-160$.

Quinn, W. (1983). Personal and family adjustment in later life. Journal of Marriage and the Family, 45, 57-73.

Robinson, W.S. (1957). The statistical measure of agreement. American Sociological Review, 22, 586-593.

Sanders, L.T., \& Seelbach, w.C. (1981). Variations in preferred care alternatives for the elderly: Family versus nonfamily sources. Family Relations, 30, 447-451. 
Sarbin, T.R. (1968). Role: Psychological aspects. In D.L. Sills (Ed.), International Encyclopedia of the Social Sciences (Vol. 13) (pp. 546-552). New York: Macmillan, Free. Sarbin, T.R., \& Allen, V.L. (1968). Role theory. In G. Linzey \& E. Aronson (Eds.), Handbook of social psychology: Vol. 1 (2nd ed.) (pp. 488-567). Reading, MA: Addison-Wesley.

Sauer, W., Seelbach, W., \& Hanson, S. (1981). Rural-urban and cohort differences in filial responsibility norms. Journal of Minority Aging, $\underline{5}, 299-305$.

Schlesinger, M.R., Tobin, S.S., Kulys, R. (1981). The responsible child and parental well-being. Journal of Gerontological Social Work, $\underline{3}, 3-16$.

Seelbach, W.C. (1977). Gender differences in expectations for filial responsibility. The Gerontologist, 17, 421-425. Seelbach, W.C. (1978). Correlates of aged parents' filial responsibility expectations and realizations. The Family Coordinator, 27, 341-350.

Seelbach, W.C. (1981). Filial responsibility among aged parents: A racial comparison. Journal of Minority Aging, 5, 286-292.

Seelbach, W.C., \& Sauer, W. (1977). Filial responsibility expectations and morale among aged parents. The Gerontologist, $17,492-499$.

Streib, G. (1965). Intergenerational relations: Perspectives of the two generations on the older parent. Journal of Marriage and the Family, 27, 469-476. 
Sussman, M. (1976). The family life of old people. In R. Binstock and E. Shanas (Eds.). Handbook of aging and the social sciences (pp. 415-449) New York: Van Nostrand Reinhold.

Wake, S., \& Sporakowski, M. (1972). An intergenerational comparison of attitudes towards supporting aged parents. Journal of Marriage and the Family, 34, 42-48. 
Appendix

Hamon Filial Responsibility Scale

1. Married children should live close to parents.

2. Adult children should take care of their parents in whatever way necessary when they are sick.

3. Adult children should give their parents financial help.

4. If children live nearby after they grow up, they should visit their parents at least once a week.

5. Children who live at a distance, more than twenty miles away, should write to their parents at least once a week.

6. Adult children should feel responsible for their older parents.

7. Older parents and adult children should be together on special occasions, such as holidays, birthdays, and anniversaries.

8. Older parents should be able to talk over matters of personal importance, that is those that deeply affect their lives, with their adult children.

9. Adult children should give their parents emotional support.

10. Adult children should be willing to sacrifice some of their personal freedom to take care of aging parents if they need it.

11. Adult children should make room for their older parents in their home in an emergency.

12. Adult children should give older parents advice when they need it. 
13. Adult children should adjust their work schedule in order to help older parents when they need it.

14. When older parents are unable to care for themselves, they should be able to live with one of their adult children.

15. Adult children should adjust their family schedule in order to help older parents when they need it.

16. Adult children should help their parents understand and use resources/services (Medicare, Meals on Wheels, and so on) that they are entitled to, when they need it.

Note. Response choices range from $4=$ strongly agree to $1=$ strongly disagree. 
Table 1

Endorsement of Hamon Filial Responsibility Scale Items By Adult Children and Their Parents

\begin{tabular}{|c|c|c|c|c|c|c|}
\hline \multirow[b]{2}{*}{ Item } & \multicolumn{3}{|c|}{ Children } & \multicolumn{3}{|c|}{ Parents } \\
\hline & Freq/N & $\%$ & Rank & Freq/N & $\%$ & Rank \\
\hline Help understand resources & $142 / 143$ & 99.3 & 1 & $139 / 143$ & 97.2 & 2 \\
\hline Give emotional support & $140 / 144$ & 97.2 & 2 & $135 / 141$ & 95.7 & 3 \\
\hline Talk over matters of import. & $139 / 144$ & 96.5 & 3 & $142 / 144$ & 98.6 & 1 \\
\hline Make room in home in emerg. & $136 / 144$ & 94.4 & 4 & $103 / 141$ & 73.0 & 7 \\
\hline Sacrifice personal freedom & $134 / 143$ & 93.7 & 5 & $115 / 142$ & 81.0 & 6 \\
\hline Care when sick & $133 / 144$ & 92.4 & 6 & $92 / 143$ & 64.3 & 9 \\
\hline Be together on spec. occas. & $123 / 143$ & 86.0 & 7 & $124 / 143$ & 86.7 & 5 \\
\hline Give financial help & $121 / 143$ & 84.6 & 8 & $58 / 141$ & 41.1 & 13 \\
\hline Give parents advice & $121 / 144$ & 84.0 & 9 & $126 / 142$ & 88.7 & 4 \\
\hline Adjust fam schedule to help & $116 / 144$ & 80.6 & 10 & $81 / 141$ & 57.4 & 10 \\
\hline Feel responsible for parent & $111 / 142$ & 78.2 & 11 & $95 / 143$ & 66.4 & 8 \\
\hline Adjust work schedule to help & $91 / 144$ & 63.2 & 12 & $59 / 140$ & 42.1 & 12 \\
\hline Parent should live w child & $87 / 143$ & 60.8 & 13 & $51 / 139$ & 36.7 & 15 \\
\hline Visit once a week & $74 / 144$ & 51.4 & 14 & $79 / 142$ & 55.6 & 11 \\
\hline Live close to parent & $46 / 143$ & 32.2 & 15 & $37 / 144$ & 25.7 & 16 \\
\hline Write once a week & $44 / 143$ & 30.8 & 16 & $56 / 142$ & 39.4 & 14 \\
\hline
\end{tabular}

Note. Ranking reflects percent of respondents who "strongly agreed" or "agreed" with each item. 
Table 2

Coefficient of Agreement for Aged Parent - Adult Child Pairs on the

Hamon Filial Responsibility Scale

Item

Measure of Agreement

Children should live close

.6294

Parent should be able to live with child

.6173

Should give parents advice when necessary

.6033

Children should write once a week

.5999

Children should visit once a week

.5987

Should be together on special occasions

.5904

Should adjust work schedule to help parent

.5389

Able to talk over matters of personal import $\quad .5357$

Children should feel responsible for parent .5153

Children should care for parent when sick .4901

Should make room in home in emergency $\quad .4900$

Should sacrifice personal freedom to care $\quad .4877$

Help parents understand and use resources $\quad .4860$

Should adjust family schedule to help parent .4732

Children should give emotional support $\quad .4610$

Children should give financial help $\quad .3618$

Total $\quad .5819$

Note. $\mathrm{N}=130$; Pairs with missing data in the HFR scale were deleted for this statistic's computation. 
Table 3

Summary of Multiple Regression Analysis For Parental Morale

Independent Variables

Parent's marital status

Parent's religious preference

Parent's income adequacy

Parent's perceived health

Religious preference $x$ income

Religious preference $x$ health

Income adequacy $\mathrm{x}$ health

$R^{2}=.405$

\section{Type}

categorical

categorical

categorical

categorical

adeq. cat. $x$ cat.

cat. $x$ cat.

cat. $x$ cat.
F value

$p$

$\begin{array}{rr}1.01 & .37 \\ .69 & .50 \\ .19 & .66 \\ .01 & .92 \\ 1.73 & .18 \\ 3.33 & .04 * \\ 4.92 & .03 *\end{array}$


Table 4

Average Morale Scores for Aged Parents by Religious Preference and Level of Health

\begin{tabular}{lcc}
\hline & \multicolumn{2}{c}{ Health } \\
\cline { 2 - 3 } Religious Preference & Good & Poor \\
\hline Protestant & 30.63 & 27.61 \\
Catholic & 30.02 & 27.84 \\
Other & 28.32 & 33.15 \\
& & \\
\hline
\end{tabular}

Note. $\mathrm{N}=119$; cases with missing data were excluded from this analysis. Possible scores on morale scale ranged from 17 to 34. 
Table 5

Average Morale Scores for Aged Parents by Adequacy of Income and Level of Health

\section{Health}

\begin{tabular}{lll} 
Adequacy of Income & Good & Poor \\
\hline Yes & 30.68 & 28.98 \\
No & 28.63 & 30.09
\end{tabular}

Note. $\mathrm{N}=119$; cases with missing data were excluded from this analysis. Possible scores on morale scale ranged from 17 to 34 . 
Appendix A

Literature Review 
Appendix A

Literature Review

This appendix describes in greater detail existing studies in the realm of filial responsibility and filial role enactment. Special attention is given to operationalization of filial responsibility, methodologies and major findings of previously conducted studies.

Filial responsibility is an attitude of personal obligation to assist aging parents. It emphasizes duty, protection and care (Schorr, 1960). Behavioral examples of filial responsibility include shared living arrangements, assistance with household tasks, shopping, personal contact, and emotional support (Seelbach, 1984). Some attribute the sense of filial responsibility to Judeo-Christian influence originating in the Fifth Commandment, which admonishes "Honor thy father and thy mother" (Schorr, 1980). Others suggest that this pervasive sense of felt obligation may be an outgrowth of feelings of indebtedness (Seelbach, 1984) or Irredeemable obligation (Berman, 1987) to one's parent. Still others argue that filial responsibility experienced by grown children is a result of friendship and mutuality, rather than indebtedness and repayment (English, 1979).

Whatever its origin, gerontologists report that there are few studies in the area of filial support norms that govern intergenerational interactions in later life (Brody, Johnsen, \& Fulcomer, 1984; Mancini \& Simon, 1984). The following review of 
literature reports on the diverse foci, methods, and intents of existing research.

\section{Parental Expectations}

A few studies have analyzed what elderly persons actually expect of their adult children. Wayne Seelbach $(1977,1978,1981)$ and his associates (Hanson, Sauer, \& Seelbach, 1983; Seelbach \& Sauer, 1977) probably conducted the most instrumental research in the area of filial responsibility norms among elderly parents. Their work investigated correlates of aged parent's filial responsibility expectations and realizations, the relationship between parental morale and expectations, and predictors of types of assistance provided by adult children. In their study of 595 low-income, elderly urbanites in Philadelphia, females, moreso than males, thought that old persons who do not wish to live alone or who are physically unable to care for themselves should live with children (Seelbach, 1977); the researchers noted no differences in parental expectations between blacks and whites (Seelbach, 1981).

Further evidence suggests that expectations of family support tend to exceed those of friends. Mancini and Simon (1984) compared the expectations of support from family, close friends and casual friends in the areas of assistance, social integration, and intimacy. Findings from their sample of 91 elderly participants indicated that expectations of family support exceeded those of friends, especially casual friends, particularly in the area of assistance. The old expected more from family in the way of lending small and large 
amounts of money in an emergency, giving unsolicited advice, intervening when personal safety is at risk, and providing housing when circumstances demand it. Similarly, Sanders and Seelbach (1981) analyzed age differences in preferences for family versus nonfamily sources of care for the old with telephone interview data from 450 individuals ranging from 18 to 90 years old. Although there were no significant differences in average ages of participants preferring family sources and nonfamily sources, whites displayed a greater preference for family care than did blacks.

What kinds of behaviors are expected of adult children? Brody and colleagues (1984) focused on opinions about appropriate filial behavior toward elderly parents and personal preferences among types of providers of various services of three generations of women $(\mathrm{N}=403$, of which 80 triads were related). Opinions elicited from situational vignettes revealed that old women preferred adult children as providers of emotional support and financial management, but not income. The majority of these women thought that adult children should adjust their family schedules and help meet expenses of professional health care for the impaired elderly mother where needed. However, these same women deemed that adjustment of work schedules and sharing of households as inappropriate (Brody, et al., 1984).

More recently Blieszner and Mancini (1987) explored the parenting role of 23 older adults, including current expectations of adult children. Qualitative and quantitative data regarding parental 
expectations disclosed that parents desired affection, assistance, responsibleness in meeting the demands of their own work and family, thoughtfulness, and open and frequent communication from their adult children. These parents believed that married children should neither live close to their parents nor should they be obligated to want a home large enough for their parents to feel free to move in. All older parents hoped that it would not become necessary to ask their children for care. If they got sick, however, the majority (78\%) wished that their children would take care of them, but most hoped to find suitable forms of care if debilitated. Adult Children's Expectations

A sparse number of studies reported filial norms endorsed by samples of adult children. Roff and Klemmack (1986), focusing on norms concerning adult children who were members of dual-earner couples, attempted to differentiate between behaviors expected of male and of female children. Taking into account the growing number of women in the labor force, they wondered to what extent traditional norms for female responsibility for aged parents still existed. A probability sample of 315 adults (mean age of 36.5 years) responded to a vignette about an elderly woman in need of some assistance. Both genders thought sons and daughters in dual-earner couples should equally share responsibilities to help and to maintain contact with their parents. Of the 18 norms examined, only 3 norms evidenced statistically significant gender differences; most adult children thought it more appropriate for sons to assist frail parents with 
yard work and daughters to aid with housework and meal preparation. The authors concluded that (a) adult children favored behaviors that facilitate independent living for both elderly parents and themselves and (b) eqalitarian norms for the care of infirm parents exists. More recently, Finley, Roberts, and Banahan (1988) interviewed 667 randomly selected adult children with elderly parents to determine potential motivators (affection) and inhibitors (role conflict or geographical distance) of attitudes of filial obligation. This study significantly contributed to existing information by analyzing filial obligation for each of four types of parental relationships (mother, father, mother-in-law, father-inlaw). Results indicated that relationships of predictor variables with filial obligation varied by gender of adult child and by parent type. For instance, for daughters (not sons), affection proved significant in predicting filial obligation in relationships with mothers, fathers, and mothers-in-law (not fathers-in-law). So too, role conflict impacted one's sense of filial duty in daughter father relationships only; the more daughters percelved role responsibilities conflicting, the less obligation they felt in their relationships with their fathers. Role conflict was not a significant predictor for either males or females for other parent types. The authors concluded by challenging the assumption that affection produces filial obligation or vice versa. 


\section{Intergenerational Studies}

In an effort to compare generational differences, a few studies have examined filfal norms among more than one generation simultaneously (Brody et al., 1984; Brody, Fulcomer, \& Lang, 1983; Davis, 1981; Schlesinger, Tobin, \& Kulys, 1981; Wake \& Sporakowski, 1972). Research on effects of women's changing roles on attitudes toward care of elderly adults among three generations of 403 Philadelphia women indicated that a sense of filial responsibility was strong among all three groups; the youngest group of women, moreso than the groups of mothers and grandmothers, believed grown children should assist elderly parents. Furthermore, grandmothers were most receptive to formal services and the youngest age group was least receptive (Brody et a1., 1983). The middle generation of women was less likely than granddaughters or grandmothers to prefer an adult child as a provider of housework and personal services (Brody, 1981). Using the 80 three-generation triads ( $N=240)$ subsample of these urban women in her analysis, Davis (1981) discovered that all three cohorts of women preferred adult children for provision of supportive services. She suggested that supportive assistance is more difficult for outsiders to provide because such services (e.g., role of confidant, counselor in decision-making, and grocery shopper) require "dependence on intimate knowledge of individual idiosyncracies" (Davis, 1981, p. 49).

In an analysis of the impact of retirement on intergenerational relationships, Streib (1965) discovered that most of his sample of 
291 retired fathers placed greatest emphasis on the maintenance of close affectional ties with their adult children. Only one-third of the children said that ties of affection were more important than financial help, whereas two-thirds felt that affection and financial help were of equal importance. Strelb suggested that older parents were not willing to jeopardize their affectional ties with children by expecting financial support, while children did not value affectional ties with their family of orientation as much as they do in their family of procreation.

Role Expectations And We11-Being

Existing research indicates that parental expectations of filial support may affect older parents' levels of well-being. Filial responsibitty expectations were inversely associated with parental morale (Quinn, 1983; Seelbach \& Sauer, 1977); the more parents expected from their children in the way of obligations surrounding care during illness, financial help, living nearby, visiting patterns and general feeling of duty, the lower their life satisfaction. Seelbach and Sauer (1977) proposed that those parents with extensive expectations may be "out of tune with their offsprings" expectations" (p. 498). Similarly, in a study of fifty elderly parent - adult children dyads, parental well-being was associated with their perceptions that their children will fulfill their roles as responsible others if crisis necessitates them to do so (Schlesinger et al., 1981). 
In summary, a few existing studies have tapped older parents (Blieszner \& Mancini, 1987; Mancini \& Simon, 1984; Seelbach, 1977, 1978, 1981) or adult children (Finley et al., 1988; Roff \& Klemmack, 1986) about the expectations they have of the filial role. In general, the sense of filial responsibility was strong, with expectations for assistance and support being greater for family than nonfamily members (Mancini \& Simon, 1984; Sanders \& Seelbach, 1981). Most researchers discovered that the most desirable filial functions had to do with the provision of emotional support (Blieszner \& Mancini, 1987; Streib, 1965) and those support services that required an intimate knowledge of the parent (Brody et al., 1984; Davis, 1981). Despite the emergence of more equalitarian norms for filial duty (Brody et al., 1983; Roff \& Klemmack, 1986), differing expectations on the basis of gender of child still existed (Finley et al., 1988; Houser, Berkman, \& Bardsley, 1985; Roff \& Klemmack, 1986). A limited number of studies examined more than one generation simultaneously (Brody et a1., 1983; Brody et al., 1984; Davis, 1981, Schlesinger et al., 1981; Wake \& Sporakowski, 1972) to learn that all generations reaffirmed the importance of fillal norms. Finally, expectations for filial responsibility impacted parental well-being (Quinn, 1983; Seelbach \& Sauer, 1977).

Parental Need and Filial Role Enactment

Situational circumstances of both older parents and adult children impact the enactment of the fillal role. Elderly parents with greater numbers of resources (1.e., intact marital relationship) 
received less help from children (Mutran \& Reitzes, 1984). Types and amounts of assistance also differed on the basis of parental need. For instance, among a sample of 499 children with white, elderly, widowed, but unimpaired mothers, the most commonly performed filial behaviors for both sons and daughters included provision of emotional support: maintaining close contact, displaying care and concern for mother, sharing personal thoughts, making mother feel useful and important, and expressing love for mother (Houser et al., 1985).

On the other hand, Adams (1970) discovered that as parental need for assistance increased, family bonds, particularly with offspring, became more important. For example, among inner city elderly of New York, the most vulnerable elderly (i.e., oldest, poorest) received the greatest amount of assistance (Cantor, 1975). In a study that compared filial expectations with realizations, those persons who were older, widowed, had low income, and were in poor health tended to expect more from their offspring. Seelbach (1978) contended that filial expectancles of old parents are usually indicative of their need levels. Neugarten (1975) found that most elderly people want to maintain their independence as long as possible, but when they can no longer manage, they expect their children to come to their aid.

Another aspect of need is that of social support. People have a number of requirements (i.e., need for recognition, for affection, for power) which only relationships with others can supply. In fact, different types of relationships seem to provide specific social support needs (Weiss, 1974). As social networks diminish, older 
persons may experience deficits in specific relational provisions. Relational losses accompanying aging may be resultant of residential relocation, retirement, departure of adult children, death of a spouse, and the like. Deficits in social support provisions may lead to distress or some type of adjustment (Weiss's, 1969, 1974). Contingent Circumstances and Role Enactment

The significance of contingent circumstances in modifying reciprocal intergenerational expectations and behaviors is often overlooked in research studies (Seelbach, 1978). In many cases, care of aging parents is thwarted because of a number of other obligations and constraints on the adult child (Brody, 1981; Miller, 1981; Treas, 1977). For example, one researcher (Cicirelli, 1983a, 1983b, 1987) examined the effects of marital disruption on filial role enactment. Cicirelli (1983b) compared 141 adult children with disrupted marriages (divorced, widowed, remarried) with 164 children with intact marriages to see if amount of help given to elderly parents differed due to marital status. Results indicated that adult children with disrupted marriages provided less help to elderly parents. They also perceived lower parental needs, felt less filial obligation, and felt more limited in helping because of job responsibilities. More recently, Cicirelli (1987) interviewed a nonprobability sample of 93 divorced adult children (69 women, 24 men) concerning their helping and interpersonal relationships with their aged parents. Overall, the divorced children perceived their parents' needs for help as quite legitimate, but found lack of 
sufficient money and time to be the major obstacles to helping. Adult children projected future help would be limited by competing demands of jobs and children.

In a study of 502 informal offspring helpers, Stoller (1983) explored the impact of employment and competing familial responsibilities on the amount of assistance provided by adult children in responding to needs of aged parents. The amount of assistance varied with level of parental need and presence or absence of parent's spouse. Married children provided less help than those not married. Of the employed offspring $(69.4 \%$ of the daughters and 83. $4 \%$ of the sons), being employed significantly reduced the number of hours of assistance by sons, but made no change for daughters. Number of children in the helper's household, regardless of their ages, did not have an impact on the amount of assistance provided by daughters. For sons, however, there was a positive relationship between number of children under 6 within the household and hours of assistance. Stoller (1983) suggested that sons assumed greater parental caregiving responsibilities when daughters or daughters-inlaw were preoccupied with the care of young children.

While employed sons provided significantly less care to aging parents than employed daughters (Stoller, 1983), employment of daughters impinged on the types of care provided to elderly parents by female offspring (Brody \& Schoonover, 1986). Using a purposive sample of married daughter caregivers ( 72 employed and 78 unemployed), Brody and Schoonover (1986) examined levels of 
assistance provided to widowed, elderly mothers in the areas of personal care; housework and laundry; meal preparation; using the telephone; managing money and arranging needed services; grocery shopping and transportation; and emotional support. Findings indicated that daughters in both work-status categories furnished the majority of assistance to aged mothers. Data from working and nonworking daughters revealed no significant differences in amount of help provided in the realms of shopping/transportation, household tasks, managing money/arranging needed services, and emotional support. Working daughters provided fewer hours of personal care and meal preparation than nonworking daughters, although caring networks in such situations tended to involve a number of other formal and informal care providers.

Recognizing the significance of gender in understanding helping behaviors to aged parents, Horowitz (1985) examined gender differences within a New York City sample of 131 sons and daughters identified as primary caregivers to an aging parent. Horowitz discovered that sons became caregivers by default, usually because of the unavailability of a female. Sons also offered less overall assistance to their parents than daughters, particularly in the areas of transportation, household chores, meal preparation, and personal care. For less gender-stereotyped or male-oriented modes of assistance (e.g., financial help) no significant gender differences in involvement existed. Sons more frequently enlisted the assistance of their wives when providing care to aged parents, reiterating the 
predominance of females in the caregiving role. Finally, sons experienced significantly less strain from caretaking than daughters, irrespective of level of involvement.

Houser, Berkman, and Bardsley (1985), too, found significant sex differences in filial role enactment. In their attempt to determine the effects of birth order and gender differences on filial behavior, they examined the prevalence of 20 types of services/activities provided by a sample of 499 children of elderly, white, unimpaired widows. Although no birth order differences resulted, daughters provided more emotional assistance, daily caretaking, and social services than sons. Sons tended to perform more advisory functions than daughters, although this difference was insignificant. When adjusting for situational differences (e.g., religiosity, education, number of hours worked weekly) between male and female offspring, the only gender difference maintained was that for provision of emotional support.

The impact of the affective quality of the parent - child relationship on filial role enactment remains controversial. Some have proposed that filial responsibility norms and actual behaviors do not simply emerge from feelings of affection for one's aged parent (Finley et a1., 1988; Jarrett, 1985). Others have found that long-standing intergenerational problems and conflicts such as a history of rejection, alienation or argument diminished the willingness of children to assist aging parents (Cicirel1i, 1983a; Simos, 1973). Still others have discovered that if a child perceived 
the relationship as characterized by fairness, understanding, trust, respect and affection (Bengston, 1973), fillal responsibility role enactment seemed more 1ikely. Cicirelli (1983a) found that strong feelings of attachment -- emotional or affectional bonds between parent and child -- led to increased attachment behaviors and influenced children's commitment to provide future help. Other relationship quality variables cited as reasons for helping older parents included: love of parent, desire to respond to perceived parental need, and feelings of gratefulness for things parent had done for child (Cicirelli, 1987).

In summary, research on filial role enactment is burgeoning as gerontologists become interested in the provision of helping behaviors from children to their aged parents. Level of parental need -- as indicated by marital status, health, age, income, size of social support network, and so on -- influenced the amount of filial role responsibility enacted by adult children (Cantor, 1975; Houser et a1., 1985; Mutran \& Reitzes, 1984). So too, contingent circumstances of adult children modified the degree to which grown offspring could realistically assist their parents. Factors such as marital disruption (Cicirel1i, 1983a, 1983b, 1987), employment status (Brody \& Schoonover, 1986; Stoller, 1983;), marital status (Brody \& Schoonover, 1986; Stoller, 1983), gender (Horowitz, 1985; Houser et al., 1985), birth order (Houser et al., 1985; Wake \& Sporakowski, 1972), and affection (Cicire11i, 1983a; Bengston, 1973; Finley et al., 1988; Jarrett, 1985) have varying effects on filial enactment. 
References

Adams, B.N. (1970). Isolation, function, and beyond: American kinship in the 1980's. Journal of Marriage and the Family, 34, 575-597.

Bengston, V.L. (1973). Progress report on the study of generations and mental health. Unpublished report submitted to National Institute on Mental Health.

Berman, H.J. (1987). Adult children and their parents:

Irredeemable obligation and irreplaceable loss. Journal of Gerontological Social Work, 10, 21-34.

Blieszner, R., \& Mancini, J.A. (1987). Enduring ties: Older adults' parental role and responsibilities. Family Relations, 36 , 176-180.

Brody, E.M. (1981). "Women in the middle" and family help to older people. The Gerontologist, 21, 471-480.

Brody,E.M., Johnsen, P.T., \& Fulcomer, M.C. (1984). What should adult children do for elderly parents? Opinions and preferences of three generations of women. Journal of Gerontology, 39, 736746.

Brody, E.M., Johnsen, P.T., Fulcomer, M.C., \& Lang, A.M. (1983). Women's changing roles and help to elderly parents: Attitudes of three generations of women. Journal of Gerontology, 38, 597-607. Brody, E.M., \& Schoonover, C.B. (1986). Patterns of parent-care when adult daughters work and when they do not. The Gerontologist, 26, 372-381. 
Cantor, M.H. (1975). Life space and the social support system of the inner city elderly of New York. The Gerontologist, 15, 2327.

Cicirelli, V.G. (1983a). Adult children's attachment and helping behavior to elderly parents: A path model. Journal of Marriage and the Family, 45, 815-824.

Cicirelli, V.G. (1983b). A comparison of helping behavior to elderly parents of adult chlldren with intact and disrupted marriages. The Gerontologist, 23, 619-625.

Cicirelli, V.G. (1987). The relationship of divorced adult children with their elderly parents. Journal of Divorce, 9 , 39-54. Davis, L.J. (1981). Service provision and the elderly: Attitudes of three generations of urban women. The Occupational Therapy Journal of Research, $1,31-52$.

English, J. (1979). What do grown children owe their parents? In 0. O'Neill \& W. Ruddick (Eds.), Having children: Philosophical and legal reflections on parenthood (pp. 351-356). New York: Oxford University. Finley, N.J., Roberts, M.D., \& Banahan, B.F. (1988). Motivators and inhibitors of attitudes of filial obligation toward aging parents. The Gerontologist, 28, 73-78.

Hanson, S.L., Sauer, W.J., \& Seelbach, W.C. (1983). Racial and cohort variations in filial responsibility norms. The Gerontologist, 23, 626-631. 
Horowitz, A. (1985). Sons and daughters as caregivers to older parents: Differences in role performance and consequences. The Gerontologist, 25, 612-617.

Houser, B.B., Berkman, S.L., \& Bardsley, P. (1985). Sex and birth order differences in filial behavior. Sex Roles, 13, 641-651. Jarrett, W.H. (1985). Caregiving within kinship systems: Is affection really necessary? The Gerontologist, 25, 5-10. Mancini, J.A., \& Simon, J. (1984). Older adults' expectations of support from family and friends. Journal of Applied Gerontology, 3, $150-160$.

Miller, D.A. (1981). The "sandwich" generation: Adult children of the aging. Social Work, 26, 419-423.

Mutran, E., \& Reitzes, D.C. (1984). Intergenerational support activities and well-being among the elderly: A convergence of exchange and symbolic interaction perspectives. American Sociological Review, 49, 117-130.

Neugarten, B. (1975). The future and the young-old. The

Gerontologist, 15, 4-9.

Quinn, W. (1983). Personal and family adjustment in later life. Journal of Marriage and the Family, 45, 57-73.

Roff, L.L., \& Klemmack, D.L. (1986). Norms for employed daughters' and sons' behavior toward frail older parents. Sex Roles, 14, $363-368$. 
Sanders, L.T., \& Seelbach, W.C. (1981). Variations in preferred care alternatives for the elderly: Family versus nonfamily sources. Family Relations, 30, 447-451.

Schlesinger, M.R., Tobin, S.S., \& Kulys, R. (1981). The responsible child and parental well-belng. Journal of Gerontological Social Work, $\underline{3}, 3-16$.

Schorr, A.L. (1960). Filial responsibility in the modern American family. (U.S. Department of Health, Education, and Welfare). Washington, DC: U.S. Government Printing Office.

Schorr, A.L. (1980). "thy father and thy mother....": A second look at filial responsibility and family policy. SSA Publication No. 13-11953. (U.S. Department of Health, Education, and Welfare). Washington, DC: U.S. Government Printing Office. Seelbach, W.C. (1977). Gender differences in expectations for filial responsibility. The Gerontologist, 17, 421-425. Seelbach, W.C. (1978). Correlates of aged parents' filial responsibility expectations and realizations. The Family Coordinator, 27, 341-350.

Seelbach, W.C. (1981). Filial responsibility among aged parents: A racial comparison. Journal of Minority Aging, 5, 286-292. Seelbach, w.C. (1984). Filial responsibility and the care of aging family members. In W.H. Quinn \& G.A. Hughston (Eds.), Independent aging: Family and living social systems perspective (pp. 92-105). Rockville, MD: Aspen. 
Seelbach, W.C., \& Sauer, W. (1977). Filial responsibility expectations and morale among aged parents. The Gerontologist, 17, 492-499.

Simos, B. (1973). Adult children and their aging parents. Social Work, $18,78-85$.

Stoller, E.P. (1983). Parental caregiving by adult children. Journal of Marriage and the Family, 45, 851-858.

Strefb, G. (1965). Intergenerational relations: Perspectives of the two generations on the older parent. Journal of Marriage and the Family, 27, 469-476.

Treas, J. (1977). Family support systems for the aged. The Gerontologist, 17, 486-491. Wake, S., \& Sporakowski, M. (1972). An intergenerational comparison of attitudes towards supporting aged parents. Journal of Marriage and the Family, 34, 42-48.

Weiss, R.S. (1974). The provisions of social relationships. In

2. Rubin (Ed.), Doing unto others (pp. 17-26). Englewood Cliffs, NJ: Prentice-Hall.

Weiss, R.S. (1969). The fund of sociability. Transaction, 6, 3643. 
Appendix B

Methodology 
Appendix B

Methodology

This appendix expounds upon the methodology utilized in this research. It provides greater detail with regard to the research site, the sampling procedure, the sample and its characteristics, variable operationalization and measurement, and methods of analysis.

Research Site

The sampling location for this investigation was the Harrisburg metropolitan area and its surrounding vicinities in the south-central region of Pennsylvania. The standard metropolitan statistical area of Harrisburg has a total population of 446,576 , of which 11.6 percent are 65 years of age or older (U.S. Bureau of the Census, 1982)

\section{Sampling Procedure}

The researcher used a two-stage probability design as described by Dillman (1978) to obtain the specialized sample required for this research. This sampling procedure first generated a list of eligible respondents who met the criteria for inclusion in the research. Callers screened community households via the telephone to determine if the residents possessed the characteristics of the target population. Telephone callers first asked persons answering the telephone $1 f$ anyone 65 years of age or older resided in the household. If more than one older adult met the selection criteria, the researcher selected the desired respondent, on the basis of 
gender, by using a table of random numbers. Questioning continued with the appropriate parent, when possible, to verify his/her address and to elicit the name and address of the identifled child partner. When the older parent had more than one child, the investigator selected the child for inclusion in the study on the basis of birth order, using a table of random numbers.

When households did not contain anyone 65 or over, callers asked the person answering the telephone if there were any residents of the household who were 21 years of age or older who had a parent at least 65 years old. If more than one adult child within the household met the criteria for inclusion, the caller selected one using a table of random numbers. When possible, the researcher spoke directly to the randomly identified participant in order to elicit the name and address of the identified parent partner. Callers asked eligible persons to participate in the research and, when they complied, informed them that they would receive a questionnaire within the week. See Appendix C for the detailed telephone interview schedule. In the first phase of the sampling process, the researcher incorporated a systematic sampling design using the Harrisburg telephone directory. The investigator determined the sampling interval by dividing the total column inches of listings by the number of names to be selected from it. The researcher identified the first listing by using a random number within the sampling interval. Beginning at the random starting point, the investigator systematically identified names using the standard interval measure 
unt11 the sample was drawn (Dillman, 1978; Sudman, 1973). In the event that the $n^{\text {th }}$ sampling interval landed upon a business or agency listing, the researcher alternated between using the preceding and subsequent residential phone number.

The investigator preferred the use of telephone directories over random-digit dialing for several reasons. First, asking for names and addresses of both the Identifled participant and the other pair member might become cumbersome over the telephone, especially for the older participants. By using a telephone directory, the researcher already knew the name and address of one pair member. This practice reduced the participant's task to verifying his/her own name and address, and supplying Information on the pair member. Second, by using the directory, callers avoided nonresidential numbers, saving a lot of unnecessary time expenditures. As the capitol of Pennsylvania, Harrisburg has numerous governmental office numbers as well as many business numbers. Refer to Table B-1 for response rates for the telephone screening survey.

The second phase of the sampling procedure involved sending out the questionnaires to the identified pairs during the fall of 1986 . Before mailing the questionnaire, the investigator typed the names of the referent parent and child on the corresponding, personalized cover-letter to serve as a reminder when the respondents filled out the questionnaires. The researcher adhered to Dillman's (1978) Total Design Method for mailed surveys when performing the second phase of the sampling procedure. With a theoretical basis which seeks to 
maximize rewards and minimize costs for the respondent, Dillman's methods have yielded response rates of $77 \%$ or better, depending upon the population under consideration. In order to enhance response rates in the study, the researcher gave special attention to construction and wording of instrument items and cover letters; order of questions; format, vertical flow, and exhaustiveness of response categories; clarity of instructions; general appearance and the attractiveness of instrument; and use of a booklet format. (See Appendices $D$ and $E$ for cover letters and questionnaires for children and parents, respectively). Although the researcher reduced the size of the children's questionnaires (booklet $5.5^{\prime \prime} \times 8.5^{\prime \prime}$ ) in accordance to Dillman's specifications, she maintained pica-size type (booklet 8.5" $x$ 11") for the elderly parent questionnaires due to increased incidence of visual impalrments among the older population.

The researcher stamped each questionnaire with an identification number to assure confidentiality. The number also permitted the respondent's name to be removed from the mailing list when he/she completed and returned the questionnaire. Dillman's (1978) Total Design Method also entailed sending follow-up mailings to encourage greater response rates. Approximately one week after the initial mailing, the investigator sent a postcard reminder to the entire sample. It expressed gratitude to those who had responded and served as a courteous reminder to those who had not. Three weeks after the original mallout, the researcher sent a letter and replacement questionnaire to nonrespondents only. It informed the participants 
that the researcher had not yet received their questionnaires, and reiterated, a little more strongly, the desire for response. Using the certified mall system, the investigator sent the final mailing seven weeks after the inftial malling. It was a little more urgent in requesting cooperation. (See Appendices D and E for follow-up correspondence to children and parents, respectively.) All of the mailings, with the exception of the postcard, included pre-addressed and stamped reply envelopes in which to return the questionnaire. The sampling procedure during this phase of the data collection yielded response rates of $79.4 \%$ for elderly parents and $77.9 \%$ for adult children, for a total of 328 participants.

Sample

One hundred forty-four pairs of adult children and their elderly parents were the subjects of this study. To be included in the study, individuals had to be 65 years of age or older and have at least one living child whose name and address they were willing to share. Adult children had to be 21 years of age or older and have a parent who was at least 65 years old to be considered eligible for inclusion. See Table B-2 for demographic characteristics of children and parents, as compared to the general population. The investigator treated the study's participants in accordance with the ethical standards of the American Psychological Association and the Human Subjects Review Board at Virginia Polytechnic Institute and State University. 
Operationalization of Dependent Variables

Psychological Well-Being. The revised version of the Philadelphia Geriatric Center Morale Scale (Lawton, 1975) measured morale, the extent to which an individual possesses a basic sense of satisfaction with self, feels integrated with the environment and society, and accepts what exists and cannot be changed (Lawton, 1976, p. 148). The seventeen item scale examined three dimensions of morale: Agitation (6 items), Attitude toward own aging (5 items), and Lonely dissatisfaction (6 items). Lawton (1975) reported that each factor has a high degree of internal consistency; the Cronbach's alphas being $.85, .81$, and .85 respectively. All of the items required dichotomous responses from respondents. Level of psychological well-being was the sum of the scale items, with possible scores ranging from 17 to 34 . The Cronbach's alpha for the summed scale used with the present sample of older parents was .84 .

The researcher selected the Philadelphia Geriatric Center Morale Scale because it is appropriate for aged subjects, as well as being relatively brief and reliable (Lawton, 1972). So too, the content of individual items and subscales appear to lend themselves to associational relationships with various dependent and independent variables in the current study. For example, persons who are highly Agitated (1.e., worry so much that they can't sleep, are afraid of a lot of things, etc.) might be less likely to experience high filial responsibility consensus. In contrast, high scores on the Attitude Toward Own Aging subscale (i.e., are as happy now as when they were 
younger, believe things are better than they thought they would be in old age, etc.) should be positively related to fillal responsibility expectations, and amount of role enactment by the child. The third factor of the PGC Morale Scale, Lonely Dissatisfaction, is also likely to be related. For instance, persons who rarely feel lonely and see enough of their friends and relatives are likely to be recipients of numerous child provisions. Amount of role enactment by the child is also likely to be high.

Amount of role enactment by adult child. A scale of 20

different types of services to elderly parents assessed the number of filial role behaviors provided for elderly parents. The helping behaviors were classifled as those measuring amount of contact (i.e., visiting, calling, writing), activities of daily living (cooking, laundry, cleaning, shopping, personal care), advisory functions (legal aid, manage finances), and psychological support (companionship, emotional support). Adult children circled the appropriate frequency of their performance of each item on a 6-point scale ranging from never (0) to daily (6). (Refer to Part C of the Child's Questionnaire found in Appendix D for a complete 1isting of items). The investigator computed scale scores by summing responses for the twenty 1tems. Enactment scores could range from 0 to 120 . Provisions of social relationships. This research used an adaptation of Russell and Cutrona's (1984) Social Provisions Scale to measure the relational functions of the adult child - aged parent pair as perceived by the elderly parent. Weiss's (1974) delineation 
of six categories of relational provisions or social support provided the theoretical underpinnings of this scale. The six social provisions in Weiss's theory are 1) attachment, a sense of security and place evidenced in relationships with spouses and very close friends; 2) social integration, a feeling of network membership in which common interests and ideas are shared and favors exchanged; 3 ) opportunity for nurturance, assuming responsibility for care of others, particularly one's children, and developing a sense of being needed; 4) reassurance of worth, a sense of competence and esteem often acquired from interaction with colleagues; 5) reliable alliance, a knowledge that one can depend on receiving assistance in time of need, obtained typically from kin; and 6) guidance, access to relationships with persons who can provide authoritative advicè, knowledge and expertise. Weiss suggested that although all of these provisions are essential for "adequate life organization," the primacy of these functions may fluctuate throughout different phases of the life course.

Russell and Cutrona (1984) operationalized each provision with two positive and two negative statements. Participants responded to the availability of each type of support on a four-point Likert scale ranging from "strongly agree" (4) to "strongly disagree" (1). The sum of the items for each provision subscale indicated the availability of each of the social provisions. The sum of all 24 items produced a scale score, ranging from 24 to 96 . With a sample of 494 older adults, Blieszner and Mancini (1985) found satisfactory 
internal consistency for each subscale and construct validity for the overall scale.

Operationalization of Independent Variables

Filial responstbility expectations. Filial responsibility

expectations are attitudes or beliefs that dictate what adult offsprings' obligations concerning the needs of their aging parents are or should be (Seelbach, 1978). This study examined normative expectations of aged parents and their adult chlldren separately. The Hamon Filial Responsibility Scale measured filial expectations and is a composite of items adapted from previous research (Brody, Johnsen, Fulcomer \& Land, 1983; Seelbach \& Sauer, 1977; Quinn, 1983). Seelbach and Sauer (1977) developed the original items reflected in numbers one through six, and Quinn (1983) used items seven through nine. The researcher derived the next six 1tems from a study performed by Brody and colleagues (1984) and constructed the final item. The 1nvestigator intended to develop a more global and comprehensive measure of filial responsibility, which included items that tapped accommodation, instrumental, contact and communicative components of the filial role. (See Part A of the child's and parent's questionnalre in Appendices $D$ and $E$, respectively for a full listing of items in the Hamon Filial Responsibility Scale).

Participants responded to each item using a 4-point Likert scale which ranged from (4) strongly agree to (1) strongly disagree. Total scale scores could range from 16 to 64 . Internal consistency (Cronbach's alpha) of the Hamon Fillal Responsibility Scale was .86 
for the parent sample and .85 for the sample of adult children. A group of experts confirmed face validity of the instrument.

Consensus on filial responsibility expectations. This variable was an index of the extent of agreement between elderly parents and their adult children concerning filial responsibility. When the two generations shared similar expectations of the adult child as a role performer of filial behaviors, high consensus existed. A large discrepancy between the two sets of expectations suggested low consensus. The major article of this document discusses statistical computation of this variable, as well as the results derived.

\section{Parental needs: Demographic characteristics of parents.} Answers to the following questions determined parental need for assistance: (a) What is your present age?, (b) What is your sex?, (c) What is your present marital status?, (d) How many years of school did you complete?, and (e) Which of the following best describes your racial or ethnic identification? Income and its percelved adequacy was another indicator of parental need. The following item tapped participants' financial resources: What is your approximate gross family income from all sources (including spouse's income), before taxes, in 1985? There were elght response categorles ranging from (1) less than $\$ 4,999$ to ( 8 ) over $\$ 35,000$. A potentially less threatening 1tem measured perceived adequacy of income through responses to: Do you feel that your present income is adequate? The question required a dichotomous response choice of yes or no. 
Another important measure of parental need was perceived health. The questionnaire employed two self-assessed health measures as operational measures of health status. The first question was "For someone your age, do you consider your health to be good, fair or poor?" In his compilation of health measures, Stahl (1982) reported that this frequently used instrument (Shanas, Townsend, Wedderburn, Frils, Milhoi, Stehouwer, 1968) is among the best single-item measures available for assessments of elderly persons' health. The second question was "How much does your health prevent you from doing what you want or need to do?" The researcher used these varfables to independently identify older sample members who theoretically have the greatest need for assistance from their children.

\section{Parental need: Size of potential support network. Several} questions probed the size of the older person's informal support network in order to give an indication of potential breadth of support. Because kin and friends generally comprise this group, the following three questions were asked: (a) How many living children do you have?, (b) How many living brothers and sisters do you have?, and (c) How many close friends do you have? Respondents wrote in the appropriate number for each of the three questions. This information identified older persons who theoretically have the greatest need.

Child's social situation. Several questions assessed children's contingent circumstances which might impinge upon their role enactment. One of these questions was: What is your present age? 
Additional questions revealed the existence of other social positions held by the child. For example, "What is your marital status?", revealed if the child was also a husband or a wife. Similarly, "How many living children do you have?" told whether or not the child also filled a parental role. "How many of these children are st111 dependent upon you for your time, money and the like?" gave an indication of the resources demanded by children. Likewise, "What is your sex?" and "Are you presently employed?" disclosed whether the respondents were daughters or sons and whether they serve in the role as employee, respectively.

Residential proximity is likely to greatly influence actual role enactment. Thus, the question measuring geographical distance between the two generations was: How close do you live to your parent named in the cover letter? Responses ranged from (1) within the same household to (8) over 6 hours away.

Measures of affectional solidarity or positive affect nominally defined the perceived quality and percelved reciprocity of interaction (Bengston \& Schrader, 1982). Bengston's (1973) Positive Affect Index tapped the affectional quality of the parent-child relationship. This instrument is composed of ten items representing five dimensions of positive affect: (a) understanding, (b) fairness, (c) trust, (d) respect, and (e) affection. The scale consists of five questions that are repeated twice, with the referent changing from "self" (child) to "other" (parent). Two sample questions are "How much do you feel your parent trusts you?" and its 
reciprocal, "How much do you trust your parent?" Response choices range from (4) very much to (1) very little. The summation score of the items provides an index of positive affect ranging from 10 to 40 . Formal tests of reliability and validity suggest the relative strength of this instrument. Test-retest reliability data revealed a correlation (rho) of .89 over the two time periods. In a test of homogeneity/dimensionality, the Cronbach's alpha was .92 (Bengston \& Schrader, 1982). Likewise, the Cronbach's alpha for this sample of adult children was .92 .

Methods of Analysis

The initial analysis consisted of descriptive statistics such as crosstabulations and frequencies to summarize sample characteristics for parents and adult children, and to examine each independent and dependent variable. The next step was to compute correlations among the independent and dependent variables. (See Tables B-4 and B-5). Hamon Filial Responsibility Scale. Cross-tabulation procedures provided preliminary assessments of the endorsement of fillal norms among parents and their adult children. See Table 1 in the major article for a visual representation of percentages and frequencies of endorsement of the 16 items. The researcher also computed means and standard deviations of the Hamon Filial Responsibility Scale items for both adult children and their older parents. Means ranged from 2.29 to 3.49 for children and 2.18 to 3.42 for older parents, on a 4point scale. For children, two items tied for having the lowest mean: living close to parents and writing to parents once a week. 
The item suggesting children should help parents understand resources available to them exhibited the highest mean among the offspring respondents. For parents, living close to parent revealed the lowest mean, while talking over matters of importance produced the highest mean score. See Table B-3 for a complete listing of means and standard deviations for the items.

In order to analyze the relationships among the 16 items of the Hamon Filial Responsibility Scale, the researcher calculated intercorrelations for the items for both adult children and elderly parents. The majority of the relationships between items were significant $(p<.05)$ for both the adult children's and older parents' responses. (See Tables $B-4$ and $B-5$ for intercorrelations of children's and parent's filial responsibility expectations, respectively).

The researcher factor analyzed the 16-1tem Hamon Filial Responsibility Scale in an effort to best summarize any clustering of variables. The varimax technique, using orthogonal rotation, identified four factors in the Hamon Filial Responsibility Scale for both children's and parents' responses: accommodation, communication, contact, and instrumental help. Most items loaded on one factor, suggesting clear dimensions within filial responsibility. In those five instances where items loaded on two factors, the second loading was relatively low. Tables $B-6$ and $B-7$ report the factor loadings for children and parents, respectively. Items in the accommodation dimension reflected flexibility in meeting parental 
needs and included things like sacrificing personal freedom to care for parent, making some room in home for parent, and adjusting work and family schedules to assist parents. Common items in the communication dimension included giving emotional support and helping parents understand resources. The contact dimension comprised of such items as living close and visiting and writing once a week. Parent and child responses had no common items in the fourth dimension. For childrens' responses, this dimension appeared to reflect instrumental help -- giving financlal help, caring when sick, and feeling responsible for parent. For parents, dimension IV suggested a confidante function as it included being together on special occasions and talking over personal matters.

When comparing filial responsibility expectations endorsed by parents with those endorsed by children, the researcher utilized Robinson's (1957) statistical measure of agreement. Unlike the Pearson correlation which measures the degree to which paired values of the two variables are proportional (when expressed as deviations from their means), Robinson's agreement measures the degree to which the two variables are identical (Robinson, 1957, p. 19). Consensus/agreement coefficients are reported in the major article of this document and displayed in Table 2 thereof.

Parental psychological well-being. The investigator employed stepwise multiple regression to assess the connection between intergenerational consensus of filial responsibility norms and parental well-belng. With the Philadelphia Geriatric Center Morale 
Scale (Lawton, 1975) representing the dependent variable, independent variables entered in the regression equation included: amount of agreement on fillal responsibility norms, parent's age, parent's marital status, parent's number of living children, parent's educational attainment, parent's race, parent's gender, parent's religious orientation, and adequacy of parent's income. Upon the identification of significant main effects, the researcher constructed a second regression model that included the significant main effects and their pairwise interactions. Successive eliminations of insignificant variables resulted in a more parsimonious model. See the major article for details of the findings.

Child's enactment of filial responsibility. Stepwise multiple regression procedures explored the importance of child's circumstantial and parental situational variables in explaining amount of filial role enactment. During this preliminary stage, the researcher entered the following main effects into the stepwise analysis: child's gender, child's marital status, child's age, number of living and number of dependent children, geographical distance from parent, child's birth order, child's affection toward parent, parent's gender, parent's marital status, parent's number of children, parent's age, parent's number of brothers and sisters, parent's number of close friends, years of education received by parent, parent's religious preference, and parent's health. 
Using the significant main effects identified in the exploratory stepwise procedure, the researcher created a second regression model which included the significant main effects and their pairwise interactions. The researcher performed successive regression analyses in an effort to eliminate unimportant variables. Refer to Appendix F, Supplementary Results and Discussion, for the findings. Social provisions of the adult child - aged parent relationship. The investigator utilized exploratory stepwise regression procedures to identify helpful main effects in explaining amount of social support provided by the intergenerational relationship. Again the researcher desired to learn the importance of parental and child situational variables which promoted the provision of social support. The exploratory stepwise regression model included: parental need variables as reflected by demographic characteristics (age, marital status, gender, adequacy of income, educational attainment, and religious preference) and size of potential support network (number of living children, number of living brothers and sisters, number of close friends), and child's social situation variables (gender, marital status, age, number of living children, number of dependent children, employment status, residential distance from parent, birth order, religious orientation, and affection toward parent).

The researcher formulated a second regression model using the significant main effects, as identified by the stepwise procedure, and their pairwise interactions. The investigator continued to reduce the model until only significant variables were included. A 
complete explanation of findings is available in Appendix F, Supplementary Results and Discussion. 
References

Bengston, V.L. (1973). Progress report on the study of generations and mental health. Unpublished report submitted to National Institute on Mental Health.

Bengston, V.L., \& Schrader, S.S. (1982). Parent-child relations. In D.J. Mangen \& W.A. Peterson (Eds.), Research instruments in social gerontology Vol. 2: Social roles and social participation. Minneapolis, MN: University of Minnesota.

Blieszner, R., \& Mancini, J.A. (1985, November). The Social

Provisions Scale: Assessing the functions of older adults' close relationships. Paper presented at the 38th Annual Scientific Meeting of the Gerontological Society of America, New Orleans. Brody, E.M., Johnsen, P.T., \& Fulcomer, M.C. (1984). What should adult children do for elderly parents? Opinions and preferences of three generations of women. Journal of Gerontology, 39, 736746.

Brody, E.M., Johnsen, P.T., Fulcomer, M.C., \& Lang, A.M. (1983). Women's changing roles and help to elderly parents: Attitudes of three generations of women. Journal of Gerontology, 38, 597-607. Dillman, D.A. (1978). Mail and telephone surveys: The total design method. New York: John Wiley \& Sons. Lawton, M.P. (1975). The Philadelphia Geriatric Center morale scale: A revision. Journal of Gerontology, 30, 85-89. 
Lawt on, M.P. (1976). The dimensions of morale. In D.P. Kent, R. Kastenbaum, \& S. Sherwood (Eds.), Research planning and action for the elderly: The power and potential of social science (pp. 144165). New York: Behavioral Science Publications. Quinn, W. (1983). Personal and family adjustment in later life. Journal of Marriage and the Family, 45, 57-73.

Robinson, W.S. (1957). The statistical measure of agreement. American Sociological Review, 22, 17-25.

Russe11, D., \& Cutrona, C.E. (1984). The Social Provisions Scale. Unpublished manuscript, College of Medicine, University of Iowa, Iowa City.

Seelbach, W.C. (1978). Correlates of aged parents' filial responsibility expectations and realizations. The Family Coordinator, $27,341-350$.

Seelbach, W.C., \& Sauer, W. (1977). Filial responsibility expectations and morale among aged parents. The Gerontologist, 17, 492-499.

Shanas, E., Townsend, P., Wedderburn, D., Friis, H., Milhoj, P., \& Stehouwer, J. (1968). old people in three industrial societies. New York: Atherton Press. Stahl, S.M. (1982). Hea1th. In D.J. Mangen \& W.A. Peterson (Eds.), Research instruments in social gerontology. Vol. 3: Health, program evaluation, and demography. Minneapolis, MN: University of Minnesota. 
Sudman, S. (1973). The uses of telephone directories for survey sampling. Journal of Marketing Research, 10, 204-207. U.S. Bureau of the Census, Current Population Reports, Series P-23, No. 138. Demographic and Socioeconomic Aspects of Aging in the United States, U.S. Government Printing Office, 1984. U.S. Bureau of the Census, Summary Characteristics for Governmental Units and Standard Metropolitan Statistical Areas: Pennsylvania No. PHC 80-3-40, U.S. Government Printing Office, 1982. Weiss, R.S. (1974). The provisions of social relationships. In Z. Rubin (Ed.), Doing unto others (pp. 17-26). Englewood Cliffs, NJ: Prentice-Hall. 
Table B-1

Telephone Screening Response Rates ( $N=833)$

\begin{tabular}{lr} 
No answer & 34 \\
Disconnected/Changed & 20 \\
Not eligible & 385 \\
\hline
\end{tabular}

Total Unuseable $\quad 439$

Refusals $\quad 185$

(including hang-ups)

Useable sample 209 
Table B-2

Demographic Characteristics of Adult Children and Elderly Parents

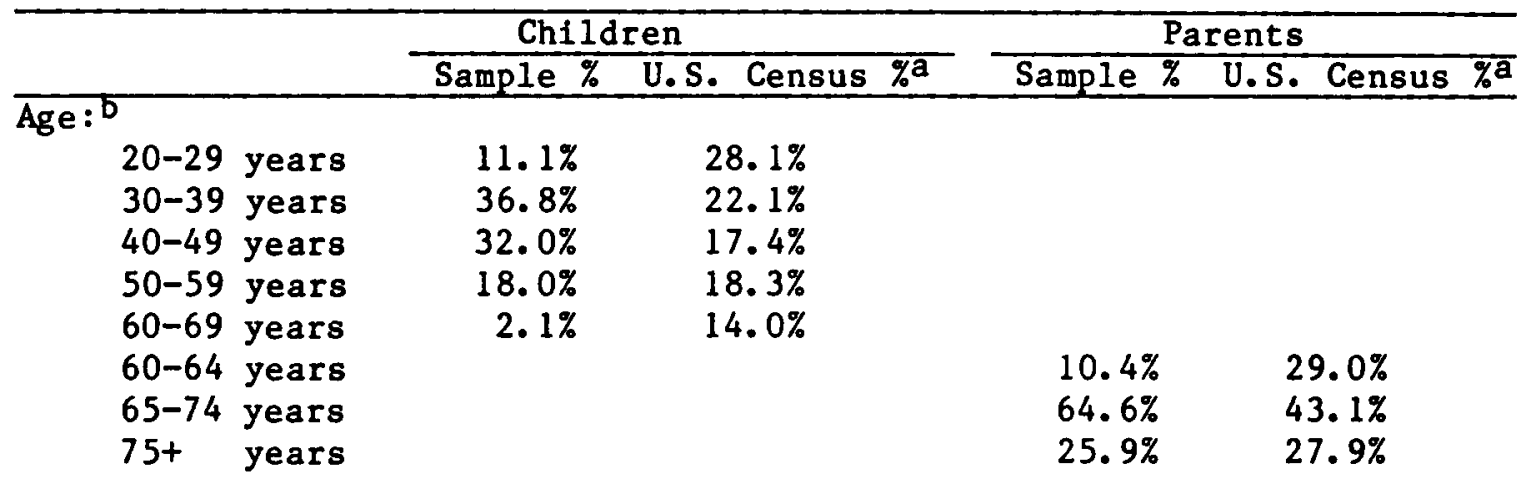

Gender :

$\begin{array}{lllll}\text { Female } & 66.0 \% & 55.8 \% & 58.7 \% & 51.9 \% \\ \text { Male } & 34.0 \% & 44.2 \% & 41.3 \% & 48.1 \%\end{array}$

Race :

$\begin{array}{lrrrr}\text { White } & 97.9 \% & 93.2 \% & 97.2 \% & 94.9 \% \\ \text { Black } & 2.1 \% & 6.8 \% & 2.1 \% & 5.0 \% \\ \text { Native American } & 0.0 \% & & .7 \% & .09 \%\end{array}$

Marital Status:

$\begin{array}{lrr}\text { Married } & 76.4 \% & 65.5 \% \\ \text { Widowed } & 3.5 \% & 31.7 \% \\ \text { Divorced/Separated } 9.7 \% & 2.8 \% \\ \text { Never Married } & 10.4 \% & 0.0 \%\end{array}$

Number of Children: ${ }^{c}$

$\begin{array}{lrr}\text { None } & 19.6 \% & 0.0 \% \\ \text { One } & 15.4 \% & 10.4 \% \\ \text { Two } & 37.7 \% & 26.4 \% \\ \text { Three or Four } & 24.5 \% & 45.8 \% \\ \text { Five or More } & 2.8 \% & 17.4 \%\end{array}$

Years of Education:d
1-6
$0.0 \%$
$5.0 \%$
$7-12$
$27.1 \%$
$57.4 \%$
13-16
$50.7 \%$
$25.5 \%$
17 or more
$22.2 \%$
$12.1 \%$ 
Children

Sample \% U.S. Census \%

Yearly Income:

$\begin{array}{lr}\text { Less than } 10,000 & 4.4 \% \\ 10,000-19,999 & 10.3 \% \\ 20,000-29,999 & 21.3 \% \\ 30,000+ & 64.0 \%\end{array}$

Employment Status:

Not at all

Part-time

$15.3 \%$

$13.9 \%$

$70.8 \%$

$\begin{array}{rr}81.9 \% & 89.8 \% \\ 8.3 \% & +10.2 \% \\ 9.7 \% & \end{array}$

$23.1 \%$

$31.5 \%$

$17.7 \%$

$27.7 \%$

Parents

Sample \% U.S. Census \%

Religious Preference:

$\begin{array}{lrr}\text { Protestant } & 70.1 \% & 72.9 \% \\ \text { Jewish } & 2.8 \% & 2.8 \% \\ \text { Catholic } & 18.7 \% & 19.4 \% \\ \text { Other } & 2.1 \% & 2.1 \% \\ \text { None } & 6.3 \% & 2.8 \%\end{array}$

Birth Order:

$\begin{array}{lr}\text { First } & 41.0 \% \\ \text { Second } & 33.3 \% \\ \text { Third } & 11.8 \% \\ \text { Fourth } & 5.6 \% \\ \text { Fifth or later } & 8.3 \%\end{array}$

a Comparison data are for Harrisburg SMSA (U.S. Census, 1982).

b Mean ages are 41.4 years for children and 71.3 years for parents.

c Average number of children is 1.88 for adult children and 3.28 for older parents.

$d$ Average years of education is 14.8 for children and 12.46 for parents.

e Median income for persons $65+$ in Harrisburg SMSA is $\$ 13,754$. 
Table B-3

Means and Standard Deviations of the Hamon Filial Responstbility Scale Items for Children and Parents

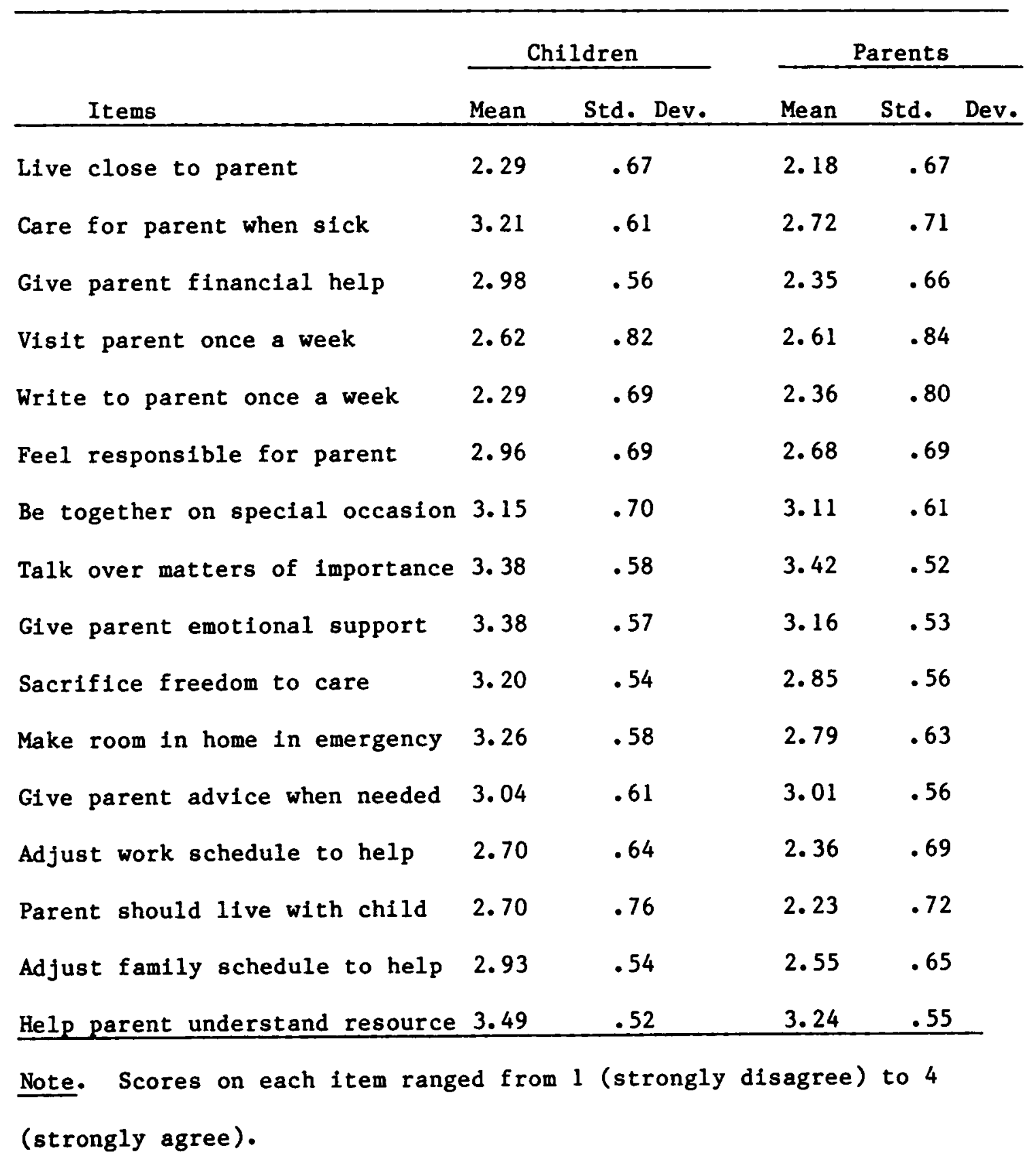




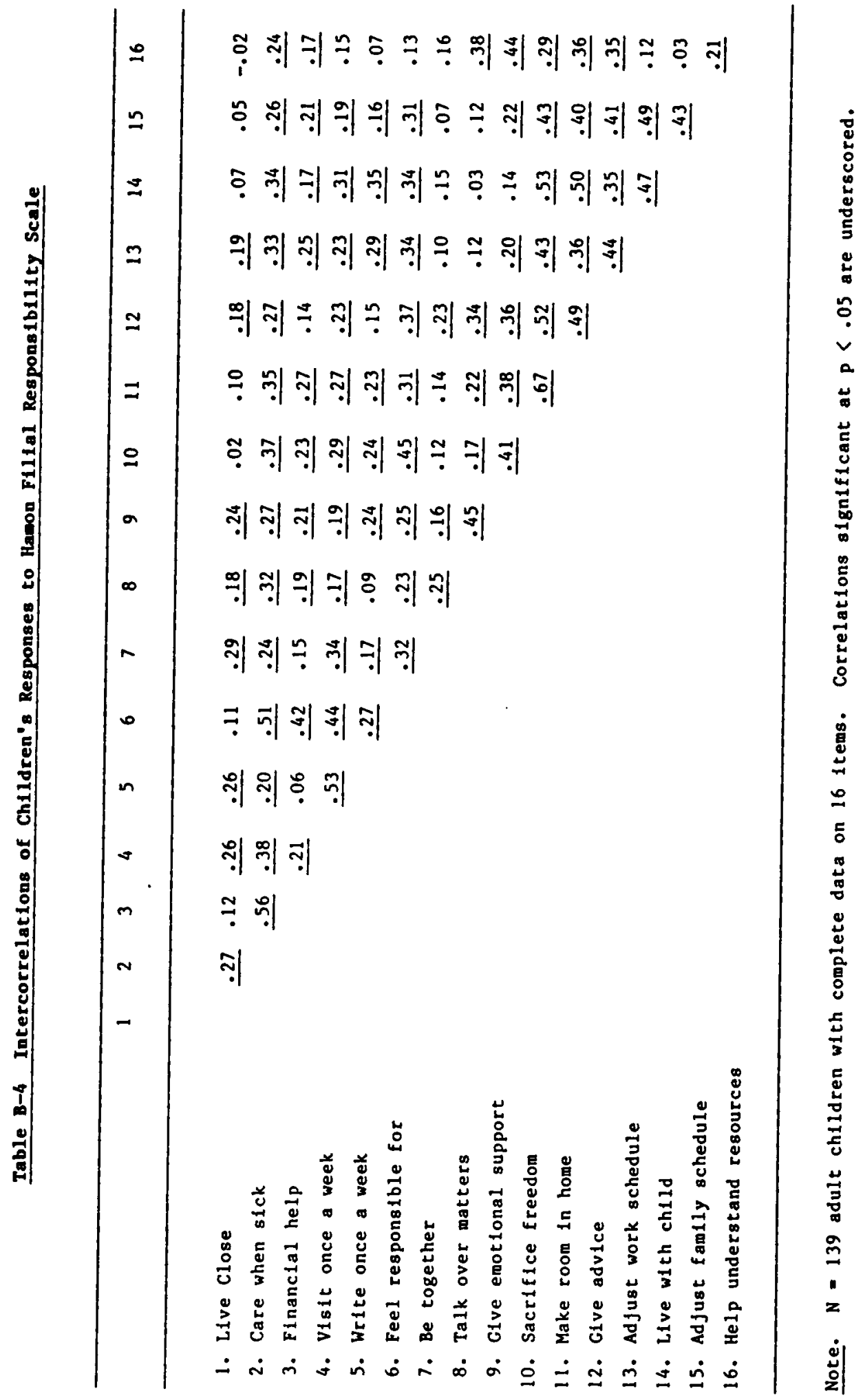




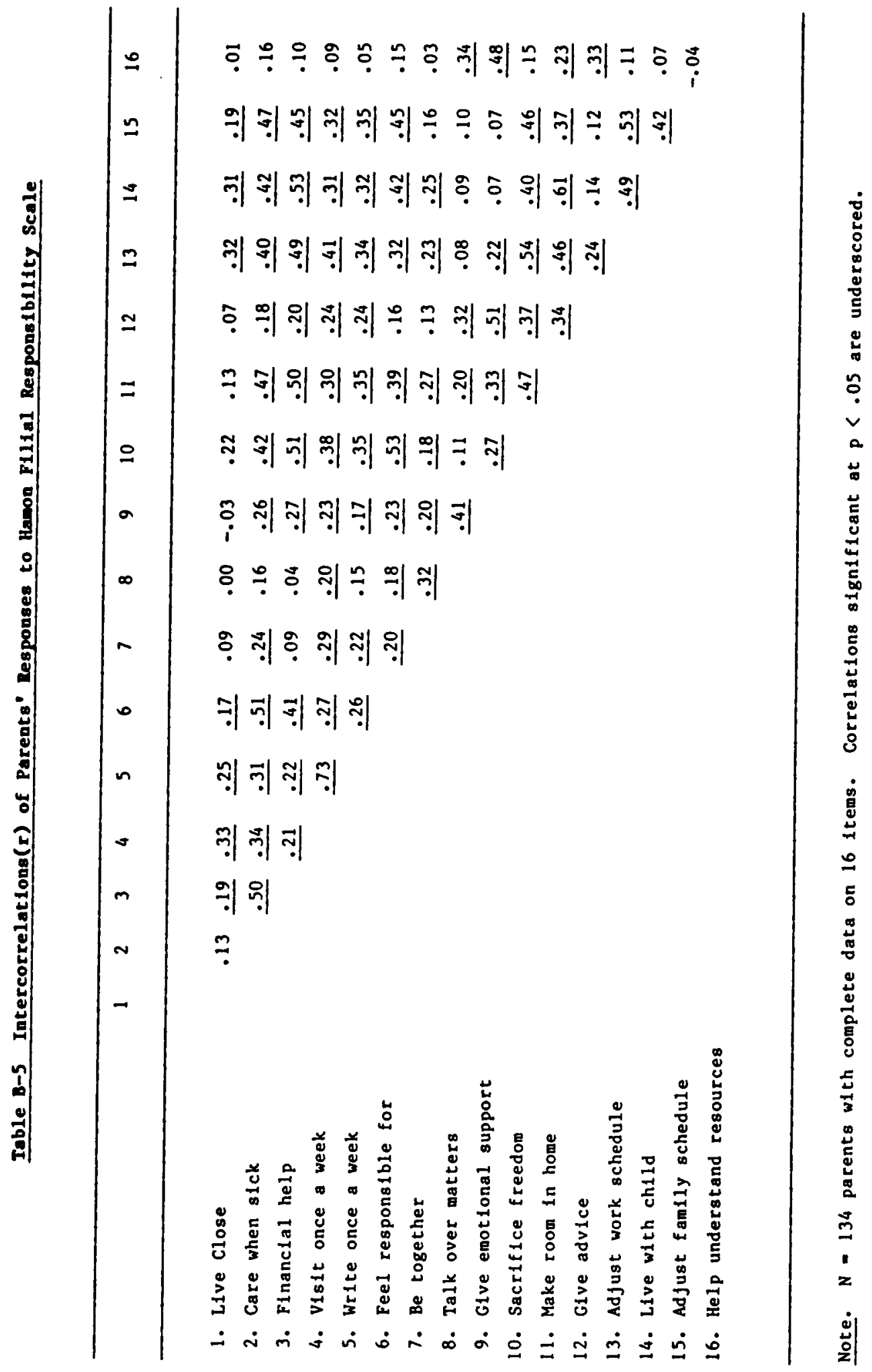


Table B-6

Factor Loadings of Four Dimensions of Hamon Filial Responsibility Scale

Items For Adult Children

\begin{tabular}{|c|c|c|c|c|c|}
\hline \multirow[b]{2}{*}{ Items } & \multicolumn{4}{|c|}{ Factors } & \multirow[b]{2}{*}{$h^{2}$} \\
\hline & I & $\overline{\text { II }}$ & III & IV & \\
\hline Live close & & & .66 & & .47 \\
\hline Care when sick & & & & .74 & .71 \\
\hline Give financial help & & & & .85 & .75 \\
\hline Visit once a week & & & .70 & & .61 \\
\hline Write once a week & .34 & & .71 & & .64 \\
\hline Feel responsible for & .37 & & & .61 & .60 \\
\hline Be together on special occasion & & & .56 & & .42 \\
\hline Talk over personal matters & & .73 & & & .61 \\
\hline Give emotional support & & .72 & & & .61 \\
\hline Sacrifice freedom to care & .77 & & & & .69 \\
\hline Make room in home & .69 & .35 & & & .62 \\
\hline Give parents advice & .57 & .47 & & & .57 \\
\hline Adjust work schedule to help & .67 & & & & .51 \\
\hline Parent should live with child & .76 & & & & .66 \\
\hline Adjust family schedule to help & .69 & & & & .51 \\
\hline Help parent understand resource & & .75 & & & .60 \\
\hline Factor & Interc & relat & & & \\
\hline Factor II & .26 & & & & \\
\hline Factor III & .32 & .16 & & & \\
\hline Factor IV & .33 & .29 & .30 & & \\
\hline
\end{tabular}

Note. Factor loadings <.30 are omitted from the table. 
Table B-7

Factor Loadings of Four Dimensions of Hamon Filial Responsibility Scale

Items for 0lder Parents

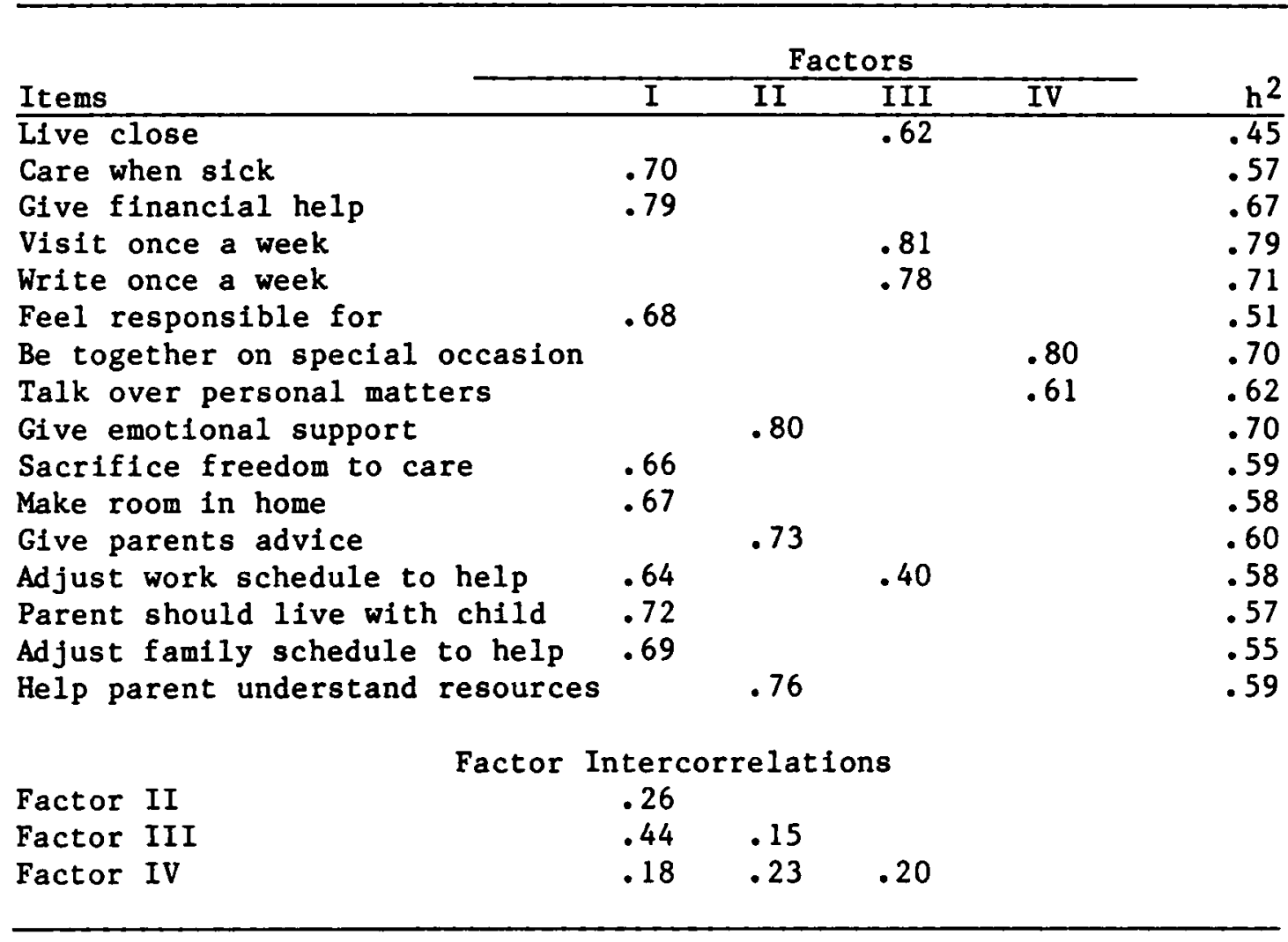

Note. Factor loadings <.30 are omitted from the table. 
Appendix C

The Telephone Interview Schedule 
Telephone Interview Schedule

Hello. My name is and I am calling from Messiah

College in Grantham. I am doing research on parents over 65 and their adult children. Your household is one of a select few chosen to participate in this study, if you are willing to do so.

I. Is anyone in your household a parent who is 65 or older?

A. If YES : $0 . K$. Including yourself, how many parents in your house are over 65? __ (If more than one eligible parent, select one using table of random numbers, and ask to speak directly to that person, if available. Mothers are odd numbers and fathers are even numbers).

1) If YES: How many children do you/ have? (If more than one child, use a random number table to choose one according to birth order. First borns will be 1 , second borns will be 2 and so on.). I would like to ask you/ and child number a few more questions about relations between parents and adult children. I would like you/ to fill out a short questionnaire that I will send in the mail. It will take about 20 minutes to complete. Since our goal is to get responses from both parent and child, I need both your/___ 's name and mailing address, as well as that of the child. Name of parent

\section{Address}

Name of child

Address 
Thank you for your help. The questionnaire should reach your house within seven days.

2) If NO: 0.K. Is there anyone in this household who has a living parent who is 65 years or older?

a). If YES: How many adult children? (If more than one eligible, use random numbers table to identify one and ask to speak directly to that person, if avallable. Females are odd numbers and males are even numbers). How many parents? (If child has more than one living parent use random number table to choose one. Mothers will be odd numbers and fathers will be even numbers). I would like to ask you/ and your/___ 's mother/father a few more questions about relations between adult chidren and their parents. I would like to send you/ a questionnaire that will take about 20 minutes to complete. Since our goal is to get responses from both child and parent, I will need both mailing addresses.

Name of child

Address

Name of parent

Address

Thank you for your help. You should recelve your questionnaire within 7 days.

B. If NO: (Go back to section A, number 2 and ask for adult child). 
Appendix D

The Cover Letter

The Child's Questionnaire

The Reminder Postcard

The Second Follow-up Mailing Letter

The Third Follow-up Mailing Letter 
Parent and Adult Child Project

September 26. 1986

Dear [ ]:

While the bond between parent and child is one of a kind, there is much about this relationship that is still not understood. I am studying parent and adult child pairs in order to learn more about this relationship in later life. This research is important because family ties Influence our everyday lives.

About one week ago during our telephone survey, you were randomly identified as one of a select group of adult children to participate in our study. Your mother/father is also being asked to participate. I urge you to answer all the questions and return your booklet as soon as possible since complete surveys from parent and adult child pairs are essential to our research. I greatly appreciate the time (about 20 minutes) that you take to complete the survey.

Each questionnaire has a code number on it to assure complete confidentiality. Your name will not be connected with your answers.

Please answer these questions about your parent named [ ]. Please think of this parent as you answer the questions.

Please call me if you have any questions. Call collect, if long distance. My telephone number is (717) 766-2511, extension 285.

Thank you very much for your help.

Sincerely,

Raeann R. Hamon

Project Director 


\section{PART A}

Adult children have many different ideas about what they should or should not do for their parents. Now, thinking specifically of your parent mentioned in the letter accompanying this questionnaire, please respond to the following statements. There are no right or wrong answers, so just give your own opinion. Circle the number from 4 to 1 which indicates how much you Agree or Disagree with each statement.

STRONGLY AGREE 4
AGREE 3
DISAGREE

2
STRONGLY

DISAGREE

1. Married children should live close to

parents.................. 4321

2. Adult children should take care of their parents in whatever way necessary when they are sick................... 4321

3. Adult children should give their parents

financial help................. 4321

4. If children live nearby after they grow up, they should visit their parents at least once

a week. . . . . . . . . . . . . 4321

5. Children who live at a distance, more than twenty miles away, should write to their parents at least once a week. . . . . . . . . . . . . 4321

6. Adult children should feel responsible for their older parents.............. 4321

7. Older parents and adult children should be together on special occasions, such as holidays, birthdays, and anniversarles. . . . . 4321

8. Older parents should be able to talk over matter of personal importance, that is those that deeply affect their lives, with their adult children................. 4321 
DISAGREE

2

9. Adult children should give their older parents emotional support... . . . . . . 4321

10. Adult children should be willing to sacrifice some of their personal freedom to take care of aging parents if they need it . . . . . . . 4321

11. Adult children should make room for their older parents in their home in an emergency . . . 43221

12. Adult children should give older parents advice when they need it. . . . . . . . . 4 4321

13. Adult children should adjust their work schedule in order to help older parents when they need it...................... 4321 14. When older parents are unable to care for themselves, they should be able to live with one of their adult children ......... . 4321 15. Adult children should adjust their family schedule in order to help older parents when they need it................... 4321

16. Adult children should help their parents understand and use resources/services (Medicare, Meals on Wheels and so forth), that they are entitled to, when they need it......... 4321

17. How would you rate your overall relationship with your parent? (Circle number)

$\begin{array}{lll}1 & \text { VERY POOR } & 4 \text { GOOD } \\ 2 & \text { POOR } & 5 \text { VERY GOOD } \\ 3 & \text { FAIR } & \end{array}$




\section{PART B}

An important part of this study surrounds the feelings that parents and children have for one another. Please answer the following questions as honestly as possible by circling the number of the best answer.

$\begin{array}{cccc}\text { VERY } & & & \text { VERY } \\ \text { MUCH } & \text { MUCH } & \text { LITTLE } & \text { LITTLE } \\ 4 & 3 & 2 & 1\end{array}$

1. How much do you feel your parent understands you?. . . . . . . . . . . . 4321

2. How much do you feel your parent trusts

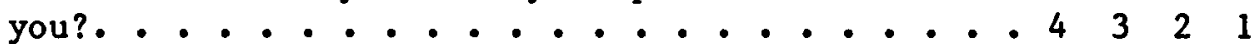

3. How fair do you feel your parent is

toward you?................. 4321

4. How much respect would you say your

parent has for you? .............. 4321

5. How much affection do you feel your

parent has for you? ............ 4321

6. How much do you understand your parent? . . 4321

7. How much do you trust your parent?. . . . . 4321

8. How fair do you feel you are toward

your parent?. . . . . . . . . . . . 4321

9. How much do you respect your parent?. . . . 4321

10. How much affection do you have

toward this parent?............... 4321 


\section{PART C}

An important purpose of this study is to learn more about what adult children actually do for their parents. Once again, think about what you do for your parent named on the cover letter as you answer the questions. Circle the number of your answer.

\begin{tabular}{ccccccc} 
& ONCE & SEVERAL & ONCE OR & & 2 OR 3 \\
& A & TIMES & TWICE A & EVERY & TIMES & \\
NEVER & YEAR & A YEAR & MONTH & WEEK & A WEEK & DAILY \\
0 & 1 & 2 & 3 & 4 & 5 & 6 \\
\hline
\end{tabular}

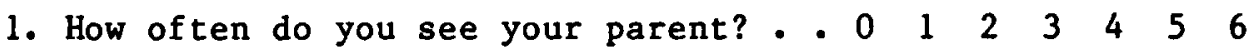

2. How often do you talk to your parent

on the phone?. . . . . . . . . . . 011233456

3. How often do you send letters or cards to your parent?.......... 011223456

4. How of ten do you provide the following

types of assistance for your parent? - •

a. Housekeeping (washing dishes, vacuuming, taking out garbage, dusting and so on) ......... 011223456

b. Cooking/Meal preparation ..... 0112234456

c. Laundry. . . . . . . . 01123456

d. Minor household repairs and maintenance. . . . . . . 011223456

e. Yardwork (mowing, weeding and so on) $0 \begin{array}{lllllll} & 1 & 2 & 3 & 4 & 5 & 6\end{array}$

f. Car care (washing, fixing) ... . 011223456

g. Shopping . . . . . . . . 011223456

h. Help with transportation (drive parent places) . . . . . . . 011223456

1. Personal care (help with bathing,

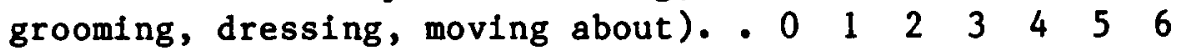

j. Help during illness. . . . . . 0112234556 


\begin{tabular}{ccccccc} 
& ONCE & SEVERAL & ONCE OR & \multicolumn{2}{c}{ OR 3} \\
NEVER & A & TIMES & TWICE A & EVERY & TIMES & \\
0 & 1 & A YEAR & MONTH & WEEK & A WEEK & DAILY \\
& & 2 & 3 & 4 & 5 & 6 \\
\hline
\end{tabular}

k. Help with important decisions. . . 0112234456

1. Manage finances. ....... 011233456

m. Financial aid. ........ 01123456

n. Legal aid........... 01123456

o. Help get parent information about resources in the community for senior citizens. -....... 011223456

p. Emotional support. . . . . . 011223456

q. Companionship (spend time together). $\begin{array}{llllllll}0 & 1 & 2 & 3 & 4 & 5 & 6\end{array}$

\section{PART D}

Finally, I would like to ask some background questions about yourself to help interpret the results. Circle the number of your answer.

1. What is your sex? (Circle number of your answer)

\section{MALE \\ 2 FEMALE}

2. What is your present marital status?
1 MARRIED
3 DIVORCED
5 NEVER MARRIED
2 WIDOWED
4 SEPARATED

3. What is your present age?

YEARS

4. How many living children do you have? CHILDREN

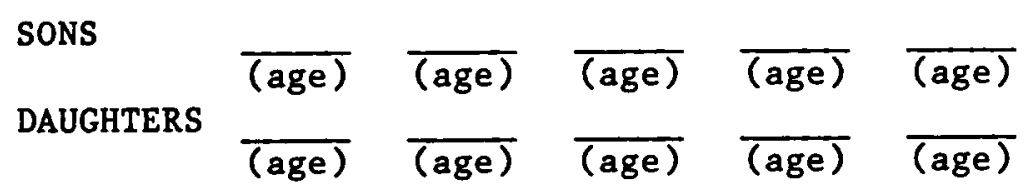

5. How many of these children are still dependent upon you for your time, money, and so forth? DEPENDENT CHILDREN 
6. How close do you live to your parent named in the cover letter? (Circle number)

1
1

7. How many living brothers and sisters do you have?

(Write in number; if you are an only child, write 0 )

BROTHERS

SISTERS

8. What is your place in the birth order of your

family? (Circle number)
1 FIRST BORN
5 FIFTH BORN
2 SECOND BORN
6 SIXTH BORN
3 THIRD BORN
7 SEVENTH BORN
4 FOURTH BORN
8 OTHER (specify):

9. How many years of school did you complete?

(Circle number)

\begin{tabular}{rrllc} 
& JUNIOR & HIGH & COLLEGE OR & POST \\
ELEMENTARY & HIGH & SCHOOL & TRADE SCHOOL & COLLEGE \\
\hline
\end{tabular}

$\begin{array}{llllllllllllllllllll}123456 & 7 & 4 & 9 & 10 & 11 & 12 & 13 & 14 & 15 & 16 & 17 & 18 & 19 & 20+\end{array}$

10. Which of the following best describes your racial or ethnic background? (Circle number)
1 BLACK
2 CHICANO
3 NATIVE AMERICAN
4 WHITE
5 ORIENTAL
6 OTHER (specify)

11. What is your religious preference? (Circle number)

$\begin{array}{ll}1 & \text { PROTESTANT } \\ 2 & \text { JEWISH } \\ 3 & \text { CATHOLIC } \\ 4 & \text { OTHER (specify) } \\ 5 & \text { NONE }\end{array}$


12. Are you presently employed? (Circle number)

1 NOT AT ALL

2 PART TIME (LESS THAN 30 HOURS PER WEEK)

3 FULL TIME ( 30 OR MORE HOURS PER WEEK)

13. What was your approximate gross family income from all sources (including spouse's income), before taxes, in 1985? (Circle number)

$\begin{array}{ll}1 & \text { LESS THAN } \$ 5,000 \\ 2 & \$ 5,000 \text { TO } \$ 9,999 \\ 3 & \$ 10,000 \text { TO } \$ 14,999 \\ 4 & \$ 15,000 \text { TO } \$ 19,999 \\ 5 & \$ 20,000 \text { TO } \$ 24,999 \\ 6 & \$ 25,000 \text { TO } \$ 29,999 \\ 7 & \$ 30,000 \text { TO } \$ 34,999 \\ 8 & \text { OVER } \$ 35,000\end{array}$

14. Do you feel that your present income is adequate? (Circle number)

$$
\begin{array}{ll}
1 & \text { YES } \\
2 & \text { NO }
\end{array}
$$

15. For someone your age, do you consider your health to be poor, fair, or good? (Circle number)

$$
\begin{array}{ll}
1 & \text { POOR } \\
2 & \text { FAIR } \\
3 & \text { GOOD }
\end{array}
$$

16. How much does your health prevent you from doing what you need or want to do? (Circle number)
1 A GREAT DEAL
2 A LITTLE
3 NOT AT ALL

(See back cover) 
Is there anything else you would like to tell us about your relationship with your parent, particularly as

related to your expectations of each other? If 80 , please use this space for that purpose.

Also, any comments you wish to make that you think may help us in future efforts to understand the parent - adult child relationship will be appreciated, either here or in a separate letter.

Your contribution to this study is greatly appreclated. If you would like a summary of results, please print your name and address on the back of the return envelope (NOT on the questionnaire). We will see that you get it. 
October 6, 1986

Last week a questionnalre was mailed to you seeking information about parent - adult child relationships. If you have already completed and returned it to us, please accept our sincere thanks. If not, your prompt response will be very much appreciated. Although your participation is voluntary, it is important that your questionnaire be included in the study if the results are to be truly representative of adult children in the Harrisburg area.

If by some chance you do not have the questionnalre, please call me immediately, (717) $766-2511$ or send me a note. I will mail another one to you.

Sincerely,

Raeann R. Hamon, Project Director

Messiah College

Grantham, PA 17027 
Parent and Adult Child Project

October 20,1986

Dear [ ]:

About three weeks ago I wrote to you asking you to participate in a parent - adult child relationship project. As of today, we have not received your completed questionnaire.

Our study will look at the expectations that adult children hold for themselves in regard to helping their parents. What you have to say on this topic is important to the study of parents in later life and their children.

I am writing to you again because although participation is voluntary, your response is important to this study. It is essential that each person in the sample return his/her questionnaire if results are to accurately express the opinions of adult children.

Please remember that you should answer the questions with your parent, [ ], in mind.

Another questionnaire is included in case you misplaced the first one. Please call me if you have any questions. My telephone number is (717) 766-2511, extension 285.

Thank you very much for your help.

Sincerely,

Raeann R. Hamon

Project Director 
Parent and Adult Child Project

November 19,1986

Dear [ ]:

Although participation is voluntary, your response is important to the success of our study about parent - adult child relationships. Past experiences suggest that those of you who have not yet responded may have quite different opinions than those who have already returned their questionnaires.

This is one of the first studies of this type ever conducted in the Harrisburg area. What you have to say is important for the accuracy of my results.

In case my other mailings did not reach you, another questionnaire is enclosed. I am grateful for the 20 minutes that you take to complete and return the survey.

Please answer the following questions about your parent named ].

Thank you for your contribution to the success of this study.

Sincerely,

Raeann R. Hamon

Project Director 
Parent and Adult Child Project

November 19,1986

Dear [ ]:

Although participation is voluntary, your response is important to the success of our study about parent - adult child relationships.

Past experiences suggest that those of you who have not yet responded may have quite different opinions than those who have already returned their questionnaires.

Your parent named [ ] has already returned his/her questionnaire. Since this study needs the response of both parent and adult child, it is important that I receive your survey. What you have to say is important for the accuracy of my results.

In case my other mailings did not reach you, another questionnaire is enclosed. I am grateful for the 20 minutes that you take to complete and return the survey.

Please answer the following questions about your parent named [ ].

Thank you for your contribution to the success of this study.

Sincerely,

Raeann R. Hamon

Project Director 
Appendix E

The Cover Letter

The Parent's Questionnaire

The Reminder Postcard

The Second Follow-up Malling Letter

The Third Follow-up Malling Letter 
Parent and Adult Child Project

September 26,1986

Dear [ ]:

While the bond between parent and child is one of a kind, there is much about this relationship that is still not understood. I am studying parent and adult child pairs in order to learn more about this relationship in later life. This research is important because family ties influence our everyday lives.

About one week ago during our telephone survey, you were randomly identified as on of a select group of parents to participate in our study. Your son/daughter is also being asked to participate. I urge you to answer all the questions and return your booklet to us as soon as possible since complete surveys from parent and adult child pairs are essential to my research. I greatly appreciate the time (about 20 minutes) that you take to complete the survey.

Each questionnaire has a code number on it to assure complete confidentiality. Your name will not be connected with your answers.

Please answer these questions about your child named I Please think of this child as you answer the questions.

Please call me if you have any questions. Call collect, if long distance. My telephone number is (717) 766-2511, extension 285.

Thank you very much for your help.

Sincerely,

Raeann R. Hamon

Project Director 
PART A

Parents have many different ideas about what their children should or should not do for them. Now, thinking specifically of your child mentioned in the letter accompanying this questionnaire, please respond to the following statements. There are no right or wrong answers, so just give your own opinion. Circle the number from 4 to 1 which indicates how much you Agree or Disagree with each statement.

STRONGLY

AGREE

4

AGREE

3

DISAGREE

2

STRONGLY

DISAGREE

1

1. Married children should live close to

parents.................. 4321

2. Adult children should take care of their parents in whatever way necessary when they

are sick..................... 4322

3. Adult children should give their parents

financlal help................. 4321

4. If children live nearby after they grow up,

they should visit their parents at least once

a week................. 4321

5. Children who live at a distance, more than

twenty miles away, should write to their parents

at least once a week. . . . . . . . . . . 4321

6. Adult children should feel responsible for

their older parents ............ . 4 321

7. Older parents and adult children should

be together on special occasions, such as

holidays, birthdays, and anniversaries. . . . 4321

8. Older parents should be able to talk over

matter of personal importance, that is those

that deeply affect their lives, with their

adult children.............. 4321 
STRONGLY

AGREE

4

AGREE

3

DISAGREE

2

STRONGLY

DISAGREE

1

9. Adult children should give their older

parents emotional support ........... 4321

10. Adult children should be willing to sacrifice

some of their personal freedom to take care of

aging parents if they need 1t.......... 4321

11. Adult children should make room for their

older parents in their home in an emergency . . . 43231

12. Adult children should give older parents

advice when they need it. . . . . . . . . 4321

13. Adult children should adjust their work

schedule in order to help older parents when

they need it. . . . . . . . . . . . . . 4321

14. When older parents are unable to care for

themselves, they should be able to live with

one of their adult children........... 4321

15. Adult children should adjust their family

schedule in order to help older parents when

they need it................... 4321

16. Adult children should help their parents

understand and use resources/services (Medicare,

Meals on Wheels, and so on) that they are

entitled to, when they need it......... 4321

\section{PART B}

Next I would like to ask you about your relationship with your child, the one mentioned in the cover letter. Please indicate how well each of these statements describes your relationship with your child. Circle the number which best reveals how strongly you Agree or Disagree.

1. I can depend on my child to help me if I

really need it. . . . . . . . . . . . . 4321

2. I feel that I do not have a close

relationship with my child............ 4321

3. I cannot turn to my child for guidance in

times of stress................. 4321 
4. My child depends on me for help. . . . . . 4321

5. My child enfoys the same social activities

that I do.................. 4321

6. My child does not view me as competent . . . 4321

7. I feel personally responsible for the

personal well-being of my child . . . . . . 4321

8. My child shares my attitudes and beliefs . . . 4321

9. I do not think my child respects my skills

and abilities................. 4321

10. If something went wrong, my child would

come to my assistance... . . . . . . . . 4321

11. I have a close relationship with my child

that provides me with a sense of emotional

security and well-being............. 4321

12. I could talk to my child about important

decisions in my life. . . . . . . . . . 4321

13. My child recognizes my competence and skills. $\begin{array}{lllll}4 & 3 & 2\end{array}$

14. My child does not share my interests and

concerns.................. 4321

15. My child does not rely on me for his/her

well being ....................... 4321

16. My child is trustworthy; I could turn to my

child for advice if I were having problems. . . . $4 \quad 3 \quad 2 \quad 1$

17. I feel a strong emotional bond with my child. $\begin{array}{lllll}4 & 3 & 2\end{array}$

18. My child cannot be depended on for aid if I

really needed it.................. 43221 
19. I do not feel comfortable talking about problems with my child. . . . . . . . . . 4321 20. My child admires my talents and skills. . . 4321 21. I feel a lack of Intimacy with my child . . 4321 22. My child does not like the things I do. . . 4321 23. I can count on my child in an emergency •. . $4 \quad 3 \quad 21$ 24. My child does not need me to care for him/her................... 4321

25. How would you rate your overall relationship with your child? (Circle number)
1 VERY POOR
4 GOOD
2 POOR
5 VERY GOOD
3 FAIR

\section{PART C}

An important part of this study is your outlook on life. Please circle the number of the most appropriate answer.

YES NO

1. Little things bother me more this year . . . 12

2. I sometimes worry so much that I can't sleep •. 12

3. I am afraid of a lot of things . . . . . . 12

4. I take things hard ... . . . . . . . . 122

5. I get mad more than I used to.......... I 2

6. I get upset easily ............. 122 
7. Things keep getting worse as I get older . . . 12

8. I have as much pep as I had last year. . . . . 12

9. As you get older you are less useful . . . . 12

10. I have a lot to be sad about. . . . . . . 12

11. I am as happy now as when I was younger . . . 12

12. Life is hard for me much of the time. . . . 12

13. I see enough of my friends and relatives. . . 12

14. I sometimes feel that life isn't worth living . 12

15. How much do you feel lonely? (Circle number)

$\begin{array}{ll}1 & \text { MUCH } \\ 2 & \text { NOT MUCH }\end{array}$

16. How satisfied are you with your life today? (Circle number)
1 NOT SATISFIED
2 SATISFIED

17. As you get older are things getting better or worse than you thought they would be? (Circle number)

1 WORSE

2 BETTER

$\underline{\text { PART D }}$

Finally, I would like to ask some background questions about yourself to help interpret the results.

Circle the number of your answer.

1. What is your sex? (Circle number of your answer)

1 MALE

2 FEMALE 
2. What is your present marital status?
1 MARRIED
3 DIVORCED
4 SEPARATED
5 NEVER MARRIED
2 WIDOWED

3. What is your present age?

YEARS

4. How many living children do you have?

CHILDREN

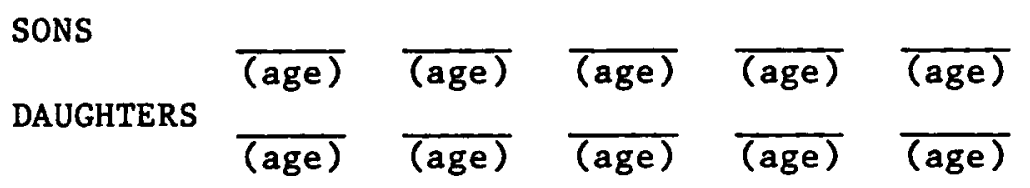

5. How close do you live to your child named in the cover letter? (Circle number)

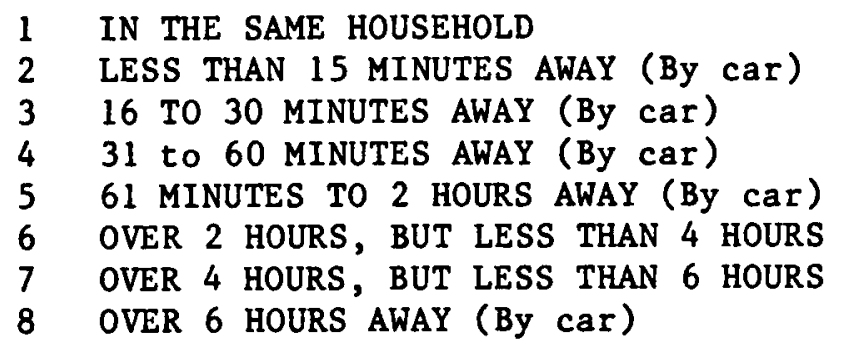

6. How many living brothers and sisters do you have?

(Write in number)

BROTHERS

SISTERS

7. How many close friends do you have? (Write in number)

CLOSE FRIENDS

8. How many years of school did you complete?

(Circle number)

\begin{tabular}{rrlll} 
& JUNIOR & HIGH & COLLEGE OR & POST \\
ELEMENTARY & HIGH & SCHOOL & TRADE SCHOOL & COLLEGE \\
\hline
\end{tabular}

$\begin{array}{llllllllllllllllllll}12 & 2 & 4 & 5 & 6 & 7 & 9 & 10 & 11 & 12 & 13 & 14 & 15 & 16 & 17 & 18 & 19 & 20+\end{array}$

9. Which of the following best describes your racial or ethnic background? (Circle number)
1 BLACK
4 WHITE
2 CHICANO
5 ORIENTAL
3 NATIVE AMERICAN
6 OTHER (specify) 
10. What is your religious preference? (Circle number)

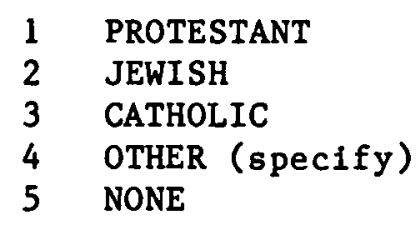

11. Are you presently employed? (Circle number)
1 NOT AT ALL
2 PART TIME (LESS THAN 30 HOURS PER WEEK)
3 FULL TIME ( 30 OR MORE HOURS PER WEEK)

12. Are you currently or have you ever provided care for you own dependent parent(s) or parent(s)-in- law? (Circle number)

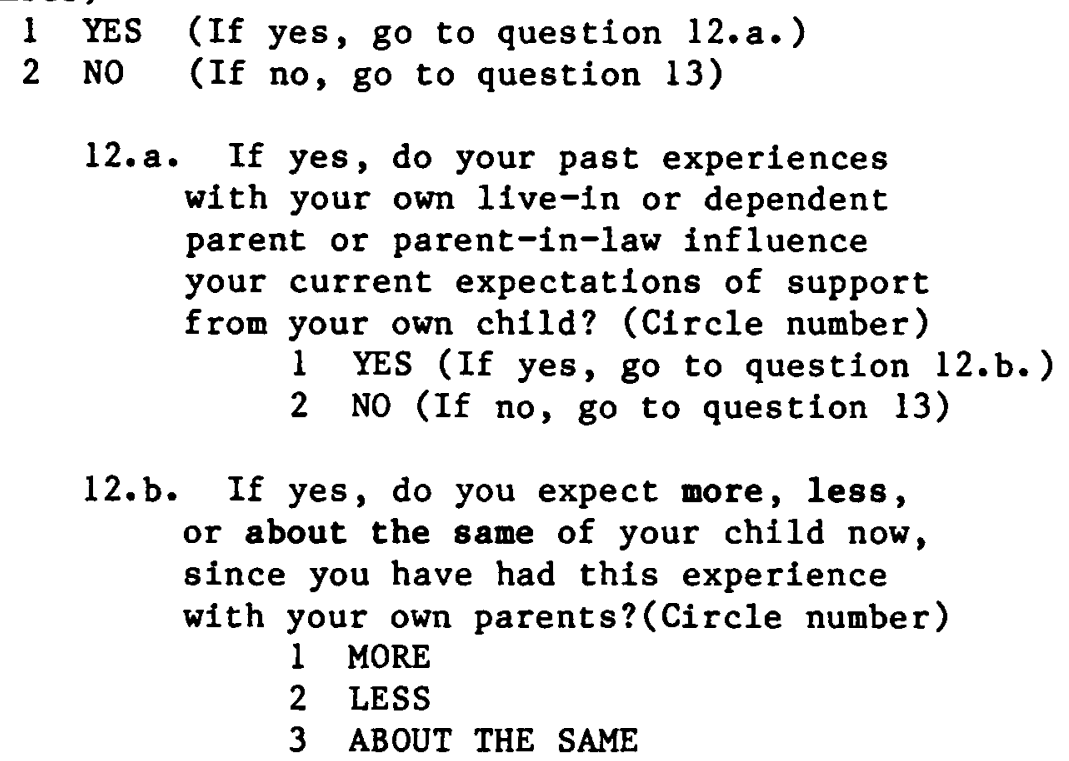

13. What was your approximate gross family income from all sources (including spouse's income), before taxes, in 1985? (Circle number)

$\begin{array}{ll}1 & \text { LESS THAN } \$ 5,000 \\ 2 & \$ 5,000 \text { TO } \$ 9,999 \\ 3 & \$ 10,000 \text { TO } \$ 14,999 \\ 4 & \$ 15,000 \text { TO } \$ 19,999 \\ 5 & \$ 20,000 \text { TO } \$ 24,999 \\ 6 & \$ 25,000 \text { TO } \$ 29,999 \\ 7 & \$ 30,000 \text { TO } \$ 34,999 \\ 8 & \text { OVER } \$ 35,000\end{array}$


14. Do you feel that your present income is adequate? (Circle number)

$\begin{array}{ll}1 & \text { YES } \\ 2 & \text { NO }\end{array}$

15. For someone your age, do you consider your health to be poor, fair, or good? (Circle number)
1 POOR
2 FAIR
3 GOOD

16. How much does your health prevent you from doing what you need or want to do? (Circle number)
1 A GREAT DEAL
2 A LITTLE
3 NOT AT ALL

(See back cover) 
Is there anything else you would like to tell us about your relationship with your adult child, particularly as related to your expectations of each other?

If so, please use this space for that purpose. Also, any comments you wish to make that you think may help us in future efforts to understand the parent - adult child relationship will be appreciated, either here or in a separate letter.

Your contribution to this study is greatly appreciated. If you would like a summary of results, please print your name and address on the back of the return envelope (NOT on the questionnaire). We will see that you get it. 
October 6, 1986

Last week a questionnaire was mailed to you seeking information about parent - adult child relationships. If you have already completed and returned it to us, please accept our sincere thanks. If not, your prompt response will be very much appreciated. Although your participation is voluntary, it is important that your questionnalre be included in the study if the results are to be truly representative of parents in the Harrisburg area.

If by some chance you do not have the questionnaire, please call me immediately, (717) $766-2511$ or send me a note. I will mail another one to you.

Sincerely,

Raeann R. Hamon, Project Director Messiah College

Grantham, PA 17027 
Parent and Adult Child Project

October 20,1986

Dear [ ]:

About three weeks ago I wrote to you asking you to participate in a parent - adult child relationship project. As of today, we have not received your completed questionnaire.

Our study will look at the expectations that parents have of their adult children. What you have to say on this topic is important to the study of parents in later life and their children.

I am writing to you again because although your participation is voluntary, your response is important to this study. It is essential that each person in the sample return his/her questionnaire if results are to accurately express the opinions of parents.

Please remember that you should answer the questions with your child, [ ], in mind.

Another questionnaire is enclosed in case you misplaced the first one. Please call me if you have any questions. My telephone number is (717) 766-2511, extension 285.

Thank you very much for your help.

Sincerely,

Raeann R. Hamon

Project Director 
Parent and Adult Child Project

November 19,1986

Dear [ ]:

Although your participation is voluntary, your response is important to the success of my study about parent - adult child relationships in the Harrisburg area. Past experiences suggest that those of you who have not yet responded may have quite different opinions than those who have already returned their questionnaires.

This is one of the first studies of this type ever conducted in the Harrisburg area. What you have to say is important for the accuracy of my results.

In case my other mailings did not reach you, another questionnaire is enclosed. I am grateful for the 20 minutes that you take to complete and return the survey. ].

Please answer the following questions about your child named

Thank you for your contribution to the success of this study.

Sincerely,

Raeann R. Hamon

Project Director 
Parent and Adult Child Project

November 19, 1986

Dear [ ]:

Although your particlpation is voluntary, your response is important to the success of my study about parent - adult child relationships in the Harrisburg area. Past experiences suggest that those of you who have not yet responded may have quite different opinions than those who have already returned their questionnaires.

Your child named [ ] has already returned his/her questionnaire. Since this study needs the response of both parent and adult child, it is important that I receive your survey. What you have to say is important for the accuracy of my results.

In case my other mailings did not reach you, another questionnaire is enclosed. I am grateful for the 20 minutes that you take to complete and return the survey. ].

Please answer the following questions about your child named

Thank you for your contribution to the success of this study.

Sincerely,

Raeann R. Hamon

Project Director 
Appendix F

Supplementary Results and Discussion 


\section{Appendix F \\ Supplementary Results and Discussion}

This appendix reports the results of the analysis of two additional hypotheses. First, do male, employed, married, and residentially distant offspring with low positive affect for parent do considerably less for their elderly parents, particularly when parental needs are low? Second, do parents who are older, widowed, female, frail and limited with regard to social support networks receive more social support (social provisions) from their adult children than those who are younger, male, healthy and have large social networks? These research questions utilized data provided by a series of items tapping actual filial behaviors (See Part $C$ of Child's Questionnaire In Appendix D) and an adaptation of Russell and Cutrona's Social Provisions Scale (1984) (See Part B of Elderly Parent's Questionnaire in Appendix E).

\section{Filial Role Enactment}

To begin, exploratory analyses in the form of stepwise regression identified those variables that helped to explain differences in level of filial role enactment. Based on the results of these analyses, the researcher built a complete regression model. The final model accounted for $63.2 \%$ of the variability in filial role enactment (See Table F-l for a summary of the independent variables included in the regression mode1). One main effect, parental marital status, was statistically significant ( $p<.01)$. More specifically, children whose parents were widowed had 
significantly higher enactment means than those whose parents were married $(p<.01)$. There were no significant differences between the widowed and divorced/separated $(p=.86)$ nor between the married and divorced/separated $(p=.20)$. (Refer to Table $F-2$ for enactment means by parents' marital status).

In addition to the effects of parental marital status, three significant interaction effects emerged -- child's gender with parental health $(p=.02)$, adult child's number of dependent children with geographical distance from parent $(p=.07)$, and affection toward parent with geographical distance from parent $(p=.02)$. A multiple comparisons procedure (pairwise t-test) isolated specific differences for each case of interaction. Starting with the interaction of child's gender and parental health status, evidence suggested that daughters exhibit greater levels of enactment than sons when parent health was fair $(p=<.01)$ or good $(p=.06)$. Male offspring had higher average enactment scores than female offspring when parent health was poor, although this difference was nonsignificant $(p=.15)$. (See Table F-3 for average enactment scores for daughters and sons across levels of parental health).

The significant interaction between number of dependent children and distance from parent indicated that this relationship between enactment and number of dependent children was not consistent across distance categories. Consequently, a single beta weight cannot adequately describe the relationship between enactment and number of children because potentially different weights must be 
considered for each level of distance. Beta weights and their significance levels are listed in Table F-4 and suggest that as the number of dependent children increased, enactment decreased. This relationship was particularly relevant when aged parents live in the same household as their adult child $(p=01)$ and when aged parents live less than 30 minutes away (by car) $(p<.01)$. When examining differences in beta weights across levels of distance, beta weights in those cases in which parents resided (a) less than 30 minutes away, (b) between 31 minutes and 2 hours away, (c) over 2 hours but less than 6 hours away, and (d) over 6 hours away significantly differed from the beta weight of adult offspring sharing the same household with their elderly parent ( $p$ values of $.07, .02, .03, .01$ respectively). In addition, the beta weight for those residing over 6 hours away also differed from that for those living less than 30 minutes from their parent $(p=.09)$.

Finally, the overall test showed interaction between distance and amount of affection for parent. The existence of this interaction suggested that the nature of the linear relationship between enactment and affection (in particular, slope or beta weight) was not consistent across various geographical distances. The general pattern of this interaction indicated that as affection increased, enactment increased, although this varied across geographical distance from parent. (Individual betas and their related significance levels are listed in Table F-5). Results revealed that the beta weight for those living in the same household 
differed significantly from that for parents less than 30 minutes away; for those 31 minutes to 2 hours away; for those over 2 hours but less than 6 hours away; and for those over 6 hours away ( $p$ values were $.08, .002, .05, .02$, respectively). In addition, beta welghts for children less than 30 minutes away and those over 2 hours but less than 6 hours away differed from that for 31 minutes to 2 hours away $(p=.02$ and $p=.09$, respectively).

\section{Social Provisions}

Exploratory stepwise multiple regression procedures also examined the impact of parental situations on the provision of social support provided by adult children, as measured by an adaptation of Russel1 and Cutrona's (1984) Social Provisions Scale. The ultimate regression model explained about $51 \%$ of the variability in the dependent variable, social provision (Refer to Table F-6 for a summary of the regression mode1). Three main effects and two interaction effects emerged as significant. Multiple comparison procedures (pairwise t-tests) isolated specific differences for each main effect and for each case of interaction. Parents' educational attainment was positively (beta weight $=.17, \mathrm{p}=.04$ ) related to the amount of social provisions provided by adult children. Distance from parent also impacted level of social provision $(p=.09)$; the average social provision was significantly greater for children who were over 6 hours away from their parents than for those over 2 hours away, but less than $6(p=08)$, and for those less than 30 minutes away $(p=.06)$. Children whose parents lived 31 minutes to 2 
hours away also had a significantly higher average provision score than did those over 2 hours away, but less than $6(p=.08)$; and those less than 30 minutes away $(p=04)$. Children's religious preference also affected amount of social provision provided $(p=.02)$; Catholic children had a higher average score than both Protestants $(p=01)$ or those having other or no religious orientations ( $p=.01$ ). (See Table F-7 for listing of average social provision scores for geographical distance, and child's religious preference).

The interaction between parent's gender and child's marital status indicated significance $(p<.01)$ in its contribution to the overall model of the dependent variable, social provision. Aged mothers had a significantly higher average social provision score than older fathers when children were married $(p<.01)$ or divorced/separated $(p<.01)$. 0lder fathers had a significantly higher average social provision score than elderly mothers when children were never married $(p=07)$. (See Table F-8 for average social provision scores).

Because of the interaction between affection and child's marital status in the overall regression model $(p=.09)$, the relationship between affection and the amount of social provision to aged parents was not consistent across all levels of marital status. Table F-9 lists the beta weights for each marital status level. These betas suggest that the average provision score increased as affection helghtened for married children $(p<.01)$ and never married children $(p=.06)$. When examining differences in beta 
weights across marital statuses, married children differed from divorced/separated children $(p=.03)$, and never married children differed from divorced/separated children $(p=.09)$.

\section{Discussion}

This study of intergenerational relationships in later life generally supported the research hypothesis which suggested that circumstantial variables, impinging upon the lives of adult children and parental need, impact the enactment of the filial role. The regression model included child's gender, employment status, affection for parent, residential distance from parent, and number of dependent children, with most of them involved in interactions. As asserted by other researchers (Brody 1981; Miller, 1981; Treas, 1977), extraneous obligations tended to constrain the adult child's likelihood of and ability to provide assistance. For instance, when adult offspring had familial obligations of their own via dependent children, the amount of filial role enactment decreased, particularly for those elderly parents who lived in the same household or within 30 minutes of thelr child's home.

Affection towards one's parent was positively related to filial role enactment, although the specific relationship varied across levels of distance. Generally speaking, as affection increased, so did the child's role enactment. This finding supported Cicirelli's (1983a) contention, on the basis of his research with 148 adult children with elderly mothers, that affectional bonds between parent 
and child led to increased attachment behaviors and influenced commitment to provide future help.

So too, parental need factors such as marital status and health were important in explaining filial role enactment. Widowed parents experienced greater amounts of assistance from their children, reiterating the significance of offspring when a spouse is no longer present (Shanas, 1979). Parental health status also impacted the enactment of filial responsibilities, although the relationship depended upon the gender of one's child; fillal role enactment by sons seemed contingent on poor parental health. In contrast to daughters whose assistance remained fairly consistent across levels of parent's health, sons appeared to reserve substantial involvement for when parents' falling health dictated it as necessary. Despite growing support for norms of equalitarianism between the sexes with regard to provision of care to parents (Brody, Johnsen, Fulcomer, \& Lang, 1983; Roff \& Klemmack, 1986), "kinkeeping" still largely appears to be the domain of women. Perhaps females encounter greater "self-role congruence" than their male counterparts when it comes to kinkeeping functions, equipping them to perceive the filial role as more compatible to their images of themselves. (Sarbin, 1968).

The second hypotheses, which suggested that parental need factors (e.g., marital status, health status, and age) and support network variables (e.g., number of close friends, number of siblings) would influence the amount of social support older parents 
would recelve from their adult children, recelved only minimal substantiation. With the exception of parent's gender, most factors thought to be important in explaining amount of social support received from the parent-child relationship were not significant. Instead, other variables emerged as important in explaining the amount of social support parents and children recelve from their relationship with each other. For example, parents' education was positively related to the amount of social provisions recelved from adult children.

Interaction effects indicated that fathers had higher social provision scores than elderly mothers when children were never married. Mothers, on the other hand, had higher average provision scores than aged fathers when children were married or divorced/separated. Although mothers seemed to do well after the marriage and possible divorce of their children, fathers lagged behind in the social provisions they recelved from such intergenerational relationships. Future research should analyze how mothers are able to maintain support provisions when children are no longer single.

Finally, average provision scores increased as affection increased for married children and never married children. One possible explanation for these differences might be that relationships between parents and their divorced/separated offspring are more strained than those between parents and married or never married offspring. Another plausible explanation could be that 
divorced/separated children are necessarily concerned about meeting the demands of their own life circumstances. For instance, Cicirelli (1983b), in a comparison of helping behavior to elderly parents of adult children with disrupted versus intact marriages, discovered that offspring of disrupted marriages gave significantly less total help to aged parents, felt less filial obligation toward them, and felt more limited in assisting them.

This analysis has gone beyond a mere analysis of filial expectations to examine actual filial behaviors and the level of social support received from the intergenerational relationship. By examining these areas more closely, family practitioners might identify those situations in which older parents might be more susceptible to need outside services and social support. 


\section{References}

Brody, E.M. (1981). "Women in the middle" and family help to older people. The Gerontologist, 21, 471-480.

Brody, E.M., Johnsen, P.T., Fulcomer, M.C., \& Lang, A.M. (1983). Women's changing roles and help to elderly parents: Attitudes of three generations of women. Journal of Gerontology, 38, 597607.

Cicirelli, V.G. (1983a). Adult children's attachment and helping behavior to elderly parents: A path model. Journal of Marriage and the Family, 45, 815-824.

Cicirelli, V.G. (1983b). A comparison of helping behavior to elderly parents of adult children with intact and disrupted marriages. The Gerontologist, 23, 619-625.

Miller, D.A. (1981). The "sandwich" generation: Adult children of the aging. Social Work, 26, 419-423.

Roff, L.L., \& Klemmack, D.L. (1986). Norms for employed daughters' and sons' behavior toward frail older parents. Sex Roles, 14 , 363-368.

Sarbin, T.R. (1968). Role: Psychological aspects. In D.L. Sills

(Ed.), International Encyclopedia of the Social Sciences

(Vol. 13) (pp. 546-552). New York: Macmillan, Free.

Shanas, E. (1979). The family as a social support system in old age. The Gerontologist, 19, 169-174.

Treas, J. (1977). Family support systems for the aged. The Gerontologist, 17, 486-491. 
Table $\mathbf{F}-1$

Summary of Multiple Regression Analysis for Filial Role Enactment

$\begin{array}{llrl}\text { Independent Variable } & \text { Type } & \text { F value } & p \\ \text { Child's gender } & \text { discrete } & .00 & .98 \\ \text { Child's no. dependent children } & \text { continuous } & 1.25 & .27 \\ \text { Distance from parent } & \text { discrete } & 1.53 & .20 \\ \text { Child's employment status } & \text { discrete } & 1.26 & .29 \\ \text { Parent's marital status } & \text { discrete } & 10.83 & <.01 * \\ \text { Parent's health } & \text { discrete } & 2.14 & .12 \\ \text { Affection for parent } & \text { continuous } & 16.27 & <.01 * \\ \text { Child's gender x parent's health } & \text { dis. x dis. } & 4.58 & .01 * \\ \text { No. dependent child. } x \text { distance } & \text { cont. x dis. } & 2.36 & .06 * \\ \text { Affection } x \text { distance } & \text { cont. x dis. } & 2.68 & .04 * \\ R^{2}=.642 & & & \end{array}$

Note. $N=124$; Cases with missing data for varlables included in regression model were excluded from the analysis. 
Table F-2

Average Enactment Scores for Adult Children by Parents'

Marital Status

Parents' Marital Status

Married

Widowed

Divorced/Separated

\section{Child's Average Enactment Score}

23.80

32.53

31.45

Note. $N=124$; Cases with missing data were excluded from analysis. Possible enactment scores range from 0 to 120. 
Table F-3

Average Enactment Scores for Adult Children by Child's Gender and Parental Health

Parental Health

Child's Gender

Good

Fair

Poor

Male

$22.25 \quad 20.24 \quad 44.57$

Female

$27.12 \quad 32.55 \quad 28.81$

Note. N=124; Cases with missing data were excluded from analysis. Possible enactment scores range from 0 to 120 . 
Table F-4

Beta Weights for the Relationship Between Enactment and Number of Dependent Children by Geographical Distance from Parent

Geographical Distance

Living in same household

Less than 30 minutes away

31 minutes to 2 hours away

Over 2 hours but less than 6 hours

Over 6 hours away
Beta Weight Unstd. Beta

$$
-1.01
$$

$-0.25$

$-3.31$

$-0.09$

$-0.59$

1.40

0.11

$-0.01$

$-0.05$ .01 .01 .96 .73 .57

Note. $\mathrm{N}=124$; Cases with missing data were excluded from analysis. 
Table $\mathbf{F}-5$

Beta Weights for Relationship Between Enactment and Child's Amount of Affection for Parent by Geographical Distance from Parent

\begin{tabular}{lccc} 
Geographical Distance & Beta Weight & Unstd. Beta & p \\
\hline Living in same household & .81 & 2.35 & .001 \\
Less than 30 minutes away & .35 & 1.02 & .001 \\
31 minutes to 2 hours away & -.08 & -.22 & .62 \\
Over 2 hours but less than 6 hours & .27 & .77 & .04 \\
Over 6 hours away & .12 & .34 & .48 \\
\hline
\end{tabular}

Note. $N=124$ Cases with missing data were excluded from analysis. 
Table F-6

Summary of Multiple Regression Analysis for Social Provisions

\begin{tabular}{|c|c|c|c|}
\hline Independent Variable & Type & $\underline{F}$ value & p \\
\hline Parent's gender & discrete & 1.17 & .28 \\
\hline Parent's years of education & continuous & 4.50 & $.04 *$ \\
\hline Parent's religious preference & discrete & 1.13 & $\cdot 34$ \\
\hline Child's marital status & discrete & 2.32 & $.08 *$ \\
\hline Distance from parent & discrete & 2.69 & $.04 *$ \\
\hline Child's religious preference & discrete & 4. 10 & $<.01 *$ \\
\hline Affection for parent & continuous & 2.29 & .13 \\
\hline Parent's gender $x$ child's marital & dis. $x$ dis. & 6.53 & $<.01 *$ \\
\hline $\begin{array}{l}\text { Affection } x \text { child's marital stat. } \\
\mathrm{R}^{2}=.539\end{array}$ & cont. $x$ dis. & 2.38 & $.07 *$ \\
\hline
\end{tabular}

Note. $\mathrm{N}=126$; Cases with missing data for variables included in regression model were excluded from analysis. 
Table F-7

Average Social Provision Scores For Levels of Significant

Independent Variables

Variable

Mean

\section{Geographical Distance}

In same household

76.08

Less than 30 minutes away

73.55

31 minutes to 2 hours away

76.59

Over 2 hours but less than 6 hours away 73.33

More than 6 hours away

76.68

Child's Religious Preference

Catholic

Protestant

Other or none
80.92

72.94

71.89

Note. N=126; Cases with missing data were excluded from analysis. 
Table F-8

Average Social Provision Scores Reported By Aged Parents by Child's Marital Status and Parent's Gender

Parent Gender

Child's Marital Status Male Female

Married $73.77 \quad 77.65$

Widowed $109.01 \quad 39.46$

Divorced/Separated

$67.27 \quad 80.88$

Never Married 80.4173 .51

Note. $N=126$; Cases with missing data were excluded from analysis. 
Table F-9

Beta Weights for the Relationship Between Social Provision and Child's Affection for Parent by Child's Marital Status

Child's Marital Status

Married

Widowed

Divorced/Separated

Never Married
Beta Weight Unstd. Beta

$.43 \quad .63<.001$

7.63

11.04

.21

$-.21$

$-.30$

.44

.35

.51

.06

Note. $\mathrm{N}=126$; Cases with missing data were excluded from analysis. 


\section{The vita has been removed from the scanned document}

